\title{
Determining gas expulsion vs retention during hydrocarbon generation in the Eagle Ford Shale
} using noble gases

\author{
D.J. BYRNE ${ }^{1 *}$, P. H. BARRY ${ }^{1,3}$, M. LAWSON ${ }^{2}$, C. J. BALLENTINE ${ }^{1}$ \\ ${ }^{1}$ Department of Earth Sciences, University of Oxford, OX1 3AN, UK \\ *Corresponding author email: david.byrne@earth.ox.ac.uk \\ ${ }^{2}$ ExxonMobil Exploration Company, Spring, TX, 77389, USA \\ ${ }^{3}$ USGS California Water Science Centre, San Diego, CA, 92101, USA
}

For submission to GCA

Number of Words $(4,822)$

Number of Figures $=9$

Number of Tables $=4$

$5^{\text {th }}$ of February 2018

\section{Abstract}

The recent proliferation of tight or unconventional petroleum bearing reservoirs as an energy resource enables a more detailed investigation of the geochemical behaviour of these systems. In addition, it provides an opportunity to improve our understanding of low-permeability crustal fluid systems at depth. Organic-rich shales are not only the source-rocks in conventional petroleum systems, but potential seals, which may be important for the trapping and storage of $\mathrm{CO}_{2}$ and/or nuclear waste. The use of noble gas isotopes as tracers of fluid provenance and physical exchange processes is well established in other crustal fluid systems. Noble gas concentrations and isotopic characteristics were determined in 10 natural gas samples produced from the Eagle Ford shale, Texas, along with the concentration and $\delta^{13} \mathrm{C}$ and $\delta \mathrm{D}$ of hydrocarbon gases. By sampling gases produced directly from unconventional reservoirs we are able to determine their residence time and the extent of interaction of these fluids with other fluids in the wider hydrogeological system. The large range in thermal maturity exhibited across the basin, as demonstrated by the range in $\delta^{13} \mathrm{C}$ of methane from -37.8 to $-47.5 \%$ VPDB, allows us to constrain the evolution of the noble gas signature within a source-rock during hydrocarbon generation and expulsion. For the first time, we show that ${ }^{36} \mathrm{Ar}$ concentrations in hydrocarbon gases are not simply controlled by solubility exchange with formation 
water. Instead, they are shown to decrease dramatically (from $2.6 \times 10^{-7}$ to $7.0 \times 10^{-9} \mathrm{~cm}^{3} \mathrm{STPcm}^{-3}$ ) with increasing thermal maturity, which we attribute to a dilution effect as more short-chain hydrocarbon compounds are generated through cracking of kerogen and secondary cracking of oil. We develop a model that combines ${ }^{36} \mathrm{Ar}$ concentrations with $\delta^{13} \mathrm{C}$ data in order to quantify the retention capacity for generated hydrocarbons, and show that between 40 to $80 \%$ of the hydrocarbons generated by the Eagle Ford shale are retained within the formation. We also calculate that radiogenic ${ }^{4} \mathrm{He}$ concentrations within the Eagle Ford are well in excess of that which could have accumulated internally since deposition and requires contributions from external ${ }^{4} \mathrm{He}$ sources. The identification of both hydrocarbon expulsion and helium addition to nominally 'tight' formations now provides a process driven and quantitative understanding of the fluid migration dynamics and processes controlling these critical formations.

\section{Introduction}

The expansion of petroleum exploration into unconventional shale oil and gas systems has fundamentally changed the global energy outlook. Unlike conventional petroleum systems (where oil and gas migrate from a source rock into a high-porosity reservoir), unconventional systems produce directly from the source-rock itself. These source-rocks are typically low-porosity organic-rich shales, and advanced production techniques such as hydraulic fracturing are required to render them economically viable (Curtis, 2002). From a geochemical perspective, this provides an opportunity to directly sample previously inaccessible fluids which are hosted in low-porosity shales, often several kilometres below the surface. The commercial production of unconventional systems has been developed and expanded rapidly in recent years, however the mechanisms controlling the behaviour and interaction of fluids within these low permeability systems remain poorly constrained (Neuzil, 1994; Prinzhofer, 2013).

Noble gas isotopes are useful for investigating crustal fluids in hydrological, volcanic and petroleum systems (Ballentine et al., 2002; Burnard et al., 2013; Holland \& Gilfillan, 2013; Byrne et al 2017). Due to their inert nature, noble gases are unaffected by the chemical alteration, redox, or biological phenomena that complicate other geochemical tracers (Ozima \& Podosek, 2002; Porcelli et al., 2002). Instead, noble gas signatures are only affected by physical processes such as mixing, diffusion, dissolution, and radiogenic production (e.g. Ballentine et al., 2002). Noble gas techniques have been previously applied to investigate the genesis and behaviour of conventional petroleum systems by constraining the timing of migration and accumulation (Torgersen \& Clarke, 1985; Marty et al., 1993; Zhou \& Ballentine, 2006; Zhou et al., 2012; Barry et al., 2016; Tolstikhin et al., 2017), quantifying relative volumes of gas and liquid phases present (Zartman et al., 1962; Bosch \& Mazor, 1988; Zaikowski \& Spangler, 1990; Ballentine et al., 1991; 1996; Barry et al., 2016, 2017, 2018), assessing the extent of fluid leakage through reservoir seals (Barry et al., 2017), and identifying the presence and provenance of fugitive gas contamination in aquifers (Darrah et al., 2014; Wen et al., 2016). We investigate here whether high-precision noble gas analysis of samples from unconventional fields will allow us to adapt 
models successfully applied in conventional systems, to develop interpretations specific to unconventional systems.

Unconventional systems present a series of new challenges in understanding fluid provenance and migration. For example, the high adsorptive capacity of the argillaceous sediments that typically make up unconventional plays (Ross \& Bustin, 2007) acts to preferentially concentrate heavy noble gases (Torgersen \& Kennedy 1999; Zhou et al., 2005), thus making solubility models that assume that the only source of heavy noble gases is that derived from groundwater difficult to use quantitatively. Additionally, the lack of secondary migration in unconventional systems lends itself to the possibility of in-situ investigation of thermal history using the thermally-driven release of radiogenic isotopes from the sediment grains into the free fluid phase (Hunt et al., 2012), as well as dating by accumulation of radiogenic ${ }^{4} \mathrm{He}$ (Wen et al., 2015).

Understanding the movement of fluids in unconventional systems is of significant importance, but remains poorly constrained. Recent work has suggested these low porosity systems may be open to both losses from the system and to contributions from underlying strata. For example, the extent of interaction between the shale gas and the overlying crust has implications for the possibility of contamination of aquifers due to hydrocarbon production (Darrah et al., 2014; Wen et al., 2016; Wen et al., 2017). Similarly, the degree to which hydrocarbons are lost from the source rock is also critical for determining volumes of petroleum released into the basin that may migrate in to conventional accumulations, as well as for making unconventional gas-in-place estimates (Ungerer, 1990; Ungerer et al., 1990; Schmoker, 2002; Jarvie et al., 2007; Clarkson et al., 2012; McGlade et al., 2013). However, recent studies also show evidence for externallysourced groundwaters contributing significantly to the noble gas inventories of in-situ unconventional hydrocarbons (Györe et al., 2017). Such an observation has important implications for the extent of fluid interaction between low-porosity shale layers and the local hydrogeological regime, which is a crucial parameter for understanding their effectiveness as a seal in carbon capture and storage (Barry et al., 2016) and nuclear waste disposal (Neuzil, 2013; Hendry et al., 2015). The extent of interaction between fluids within the shale and those in the surrounding stratigraphy can be defined in many ways, and broadly described as the extent of open vs closed system behaviour. For the purposes of this study concerning the behaviour of fluids during hydrocarbon generation, we consider the expulsion efficiency of methane to be defined as the quantity of methane expelled from the source-rock compared to the total amount generated.

Thermal maturity is a key concept in hydrocarbon generation, and refers to the extent of thermallydriven destruction (or 'cracking') of longer chain organic carbon compounds into shorter chains (Lewan, 1993). Low maturity hydrocarbon fluids typically consist of longer, complex oil molecules, whilst high maturity fluids consist primarily of simple gas compounds such as methane $\left(\mathrm{CH}_{4}\right)$, ethane $\left(\mathrm{C}_{2} \mathrm{H}_{6}\right)$, and propane $\left(\mathrm{C}_{3} \mathrm{H}_{8}\right)$. By considering samples over a significant maturity range we plan to constrain the evolution of noble gas signatures within the source rock during the hydrocarbon generation process. This allows us to address a number of key unanswered questions such as the extent to which the source rock behaves as an open or 
closed system during hydrocarbon generation, the influence of groundwater during the generation process, and the propensity for hydrocarbon storage within the shale versus expulsion (e.g. Bernard \& Horsfield, 2014).

\section{Geological background}

The Eagle Ford Formation comprises a series of organic-rich marls, limestones and bentonites deposited in the Maverick Basin of the Cretaceous Western interior seaway of North America during the Late Cretaceous (Cenomanian to Turonian) (Robison, 1997). The Formation underlies much of south Texas, where it has been targeted for unconventional oil and gas production since 2008, and is now one of the most prolifically produced unconventional fields worldwide (Clarke et al., 2016). Due to the regional dip of the formation to the south-east, the Eagle Ford has been buried to different levels of thermal maturity across the region, with wells to the north-west producing oils and associated solution gases, and wells to the South-East producing drier, methane-rich gas (Donovan et al., 2016). This study targeted wells from a range of maturities across the Eagle Ford formation, and aims to use noble gas analysis to characterise the behaviour of subsurface fluids in low porosity hydrocarbon systems across a range of thermal maturity levels. We present noble gas isotope and concentration data, alongside bulk gas composition and isotopic data, from the Eagle Ford shale oil and gas play in south Texas, USA (Figure 1).

\section{Methodology}

\subsection{Sample collection}

Samples were collected directly from producing well heads in the Eagle Ford area; a total of 10 samples were taken from 6 different lease areas. Samples for noble gas analysis were collected in $10 \mathrm{~mm}$ diameter, refrigeration-grade copper tubes, which were connected using tygon tubing to a 2-stage pressure regulator attached directly to the wellhead. The regulator was used to step down the pressure from the wellstream to 1-2bar. The copper tubes were then flushed with the produced gas for 10 minutes to avoid air contamination, before being sealed with stainless steel clamps (Weiss, 1968). In addition, samples for hydrocarbon gas geochemistry analysis were collected in industry-standard $300 \mathrm{~cm}^{3}$ valve-sealed stainlesssteel cylinders, which were flushed for 5 minutes to avoid air contamination. These were then shipped to GeoMark Research LTD in Lafayette, Louisiana, USA for bulk gas composition and C and $\mathrm{H}$ isotope analysis of major hydrocarbon species using standard procedures that are described in detail in Zumberge et al., (2012).

\subsection{Analytical techniques}

Noble gas analysis was carried out in the Noble Laboratory at the Department of Earth Sciences, University of Oxford. Samples were interfaced with a vacuum line and expanded into a calibrated volume where pressure was recorded using a Baratron capacitance manometer. The sample was then expanded onto a Ti-sponge getter initially held at $950^{\circ} \mathrm{C}$, and then cooled to room temperature, in order to remove reactive gases from the sample. The gas was then further cleaned using a dual getter system consisting of a SAES GP-50 
getter at $250^{\circ} \mathrm{C}^{\circ}$ and a SAES NP-10 getter at room temperature. A small aliquot of sample was then isolated and measured for bulk gas composition on a Hiden Analytical HAL-201 quadrupole mass spectrometer, both to allow a preliminary identification of noble gas concentrations, as well as ensuring sample purification had been achieved. The sample was then expanded into a multi-stage cryogenic trap consisting of a water-trap held at $180 \mathrm{~K}$, a stainless-steel trap held at 24K (trapping $\mathrm{Ar}, \mathrm{Kr}$ and $\mathrm{Xe}$ ), and an activated charcoal trap held at 10K (trapping $\mathrm{He}$ and $\mathrm{Ne}$ ).

The different noble gas species were then separated by sequentially raising the temperature of the traps. Firstly, He was released and measured on a ThermoScientific Helix SFT multicollector mass spectrometer. The remaining noble gases were then measured on a ThermoScientific Argus VI multicollector mass spectrometer. Ne and Ar were analysed separately, but due to the release temperatures of $\mathrm{Kr}$ and $\mathrm{Xe}$ overlapping, they were measured simultaneously using a peak-jumping procedure. In each sample, the concentration of all 23 stable noble gas isotopes were determined.

Several internal standards were run each day in order to monitor the overall stability and reproducibility of the system. Blanks and air standards were both run on a weekly basis using the same procedure as samples. Blank corrections were $<0.5 \%$ in all cases for $\mathrm{He}$ and $\mathrm{Ne},<2 \%$ for $\mathrm{Ar}$, and $<0.1 \%$ for $\mathrm{Kr}$ and Xe. Automatic air standards were run each night to monitor machine reproducibility. ${ }^{20} \mathrm{Ne}$ signals were corrected for ${ }^{40} \mathrm{Ar}^{++}$interference following Niedermann et al., $1993 ;{ }^{44} \mathrm{CO}_{2}^{++}$was monitored but levels were found to be insignificant compared to ${ }^{22} \mathrm{Ne}$ signals in all cases.

\section{Results}

\subsection{Bulk gas composition and stable isotopes}

Results are presented for samples from 10 wells within the Eagle Ford field, major gas species composition and stable isotope results are shown in table 1. The produced gases consist primarily of methane $\left(C_{1}\right)$, ranging from 67 - 92 mole \%, with longer chain hydrocarbons making up most of the remainder: 3.6$15.8 \%$ ethane $\left(C_{2}\right)$ and $0.5-9.6 \%$ propane $\left(C_{3}\right)$. There is a large range of gas dryness from 2.7 to 22.9 , where gas dryness is a measure of the proportion of heavier, 'wetter' gas species relative to methane, defined as $\frac{C_{1}}{C_{2}+C_{3}}$ (Bernard et al., 1976). Gas dryness is often interpreted to be an indicator of hydrocarbon maturity, as at higher temperatures or over longer time periods at elevated temperatures, longer-chain hydrocarbons will 'crack' into shorter chain molecules, increasing the relative proportion of short-chain molecules such as methane (Behar et al., 1997). Minor components include $\mathrm{CO}_{2}(0.7-3.9 \%)$ and $\mathrm{N}_{2}(0.07-0.42 \%)$.

Stable carbon and hydrogen isotopes of methane show a large range from $\delta^{13} \mathrm{C}_{\mathrm{C} 1}=-47.5$ to $-37.8 \%$ 。 (VPDB) and $\delta D_{C 1}=-167$ to $-261 \%$ (VSMOW). $\delta^{13} C_{C 1}$ and $\delta D_{C 1}$ are strongly correlated $\left(R^{2}=0.96\right)$, and fall within the expected range for thermogenic hydrocarbons (Schoell, 1980; Clayton, 1991; Whiticar, 1994). Like gas dryness, $\delta^{13} \mathrm{C}$ of methane is also often considered as an indicator of hydrocarbon maturity, as during hydrocarbon generation, bonds containing the lighter ${ }^{12} \mathrm{C}$ atoms have a higher propensity to crack. As a result, 
the petroleum compounds formed earlier in the generation process tend to contain a higher proportion of the lighter ${ }^{12} \mathrm{C}$ isotope relative to the rare ${ }^{13} \mathrm{C}$ isotope, and thus have lower (more negative) $\delta^{13} \mathrm{C}$ ratios. $\delta^{13} \mathrm{C}$ of methane in the samples shows a broad positive correlation with gas dryness, although the relationship is not 1:1. This behaviour is consistent with petroleum generation models that predict slightly drier gases during the early stages of petroleum formation (Lorant et al., 1998). Carbon isotope ratios for the heavier hydrocarbon species are consistently higher than methane in every sample: $\delta^{13} C_{C 2}=-33.5$ to $-17.39 \%$ and $\delta^{13} C_{C 3}=-29.4$ to 14.0\% . As much of the following discussion and interpretation centres on variations with respect to maturity, samples are labelled $A$ through to $F$, going from lowest to highest maturity as interpreted from the carbon isotope ratio of methane. We consider C-isotopes to be the most reliable indicator of maturity in this system, due to being unaffected by phase partitioning between oil and gas, as gas dryness could be (Bernard \& Faber, 1988). Other maturity indicators such as molecular biomarker ratios are not present in the higher-maturity gases in this system. Samples from wells within the same lease, for which maturity is approximately equal, are distinguished by number (A1, A2; B1, B2 etc.).

\subsection{Noble gas isotopic analysis}

\subsubsection{Helium}

Helium isotope ratios $\left({ }^{3} \mathrm{He} /{ }^{4} \mathrm{He}\right.$ ) ratios are reported relative to the atmospheric ratio (where air=1 $\mathrm{R}_{\mathrm{a}}$ ), and show a range from $0.015-0.16 \mathrm{R}_{\mathrm{a}}$ (Tables 1 and 2). ${ }^{4} \mathrm{He} /{ }^{20} \mathrm{Ne}$ ratios are $>5000$ for all samples, which by comparison with the atmospheric ${ }^{4} \mathrm{He} /{ }^{20} \mathrm{Ne}$ of 0.32 suggests that there is negligible atmospheric $\mathrm{He}$ contribution. The low ${ }^{3} \mathrm{He} /{ }^{4} \mathrm{He}$ ratios suggest that the majority of the helium is derived from crustal radiogenic production, for which typically ${ }^{3} \mathrm{He} /{ }^{4} \mathrm{He}=0.02 \mathrm{R}_{\mathrm{a}}$ (Ballentine \& Burnard, 2002). However some samples show a small and variable contribution of mantle fluids, for which sub-continental lithospheric mantle ${ }^{3} \mathrm{He} /{ }^{4} \mathrm{He}=6.1 \mathrm{R}_{\mathrm{a}}$ (Gautheron et al., 2002; Day et al., 2015). Using a simple 2-endmember mixing model, we can quantify mantle helium contributions to ${ }^{4} \mathrm{He}$ of between $0.14 \%$ and $2.57 \%$. Helium isotope ratios appear to be dependent on geographic location, with all pairs of samples from the same lease having almost indistinguishable ${ }^{3} \mathrm{He} /{ }^{4} \mathrm{He}$ values. Previous work has shown the presence of mantle fluids to be strongly influenced by local structural geometry, with major faults seeming to increase the presence of mantle fluids (Hooker et al., 1985; Oxburgh et al., 1986). However, the spatial resolution of this sample set is not high enough to make detailed inferences about the distribution of mantle fluids in the wider area. The presence of mantle helium in these samples is strong evidence for open system behavior of the Eagle Ford shale over geological time. Helium concentrations $\left({ }^{4} \mathrm{He}\right)$ range from 1.39 to $5.26 \times 10^{-5} \mathrm{~cm}^{3} \mathrm{STPcm}^{-3}$, and show no appreciable correlation with ${ }^{3} \mathrm{He} /{ }^{4} \mathrm{He}$ (figure 2).

\subsubsection{Neon}

Neon isotope ratios $\left({ }^{20} \mathrm{Ne} /{ }^{22} \mathrm{Ne}\right.$ and $\left.{ }^{21} \mathrm{Ne} /{ }^{22} \mathrm{Ne}\right)$ show an excess of the nucleogenically-produced ${ }^{21} \mathrm{Ne}$ and ${ }^{22} \mathrm{Ne}$ isotopes, with the trend following the empirically-derived crustal neon production line (Kennedy et al., 1990). Although there is some scatter around this line, shown in figure 3 , it is notable that previous noble gas studies of unconventional hydrocarbon systems also show a large dispersion in neon isotope ratios relative 
to this reference (Wen et al., 2015; Zhou et al., 2005). It is possible that there is some variable effect of massdependent fractionation, unique to low-porosity unconventional systems, that results in these deviations. Neon concentrations $\left({ }^{20} \mathrm{Ne}\right)$ range from 8.7 to $55.6 \times 10^{-10} \mathrm{~cm}^{3} \mathrm{STPcm}{ }^{-3}$ and are strongly dependent on maturity, with higher maturity samples having systematically lower Ne concentrations. This can be seen in the relationship of $\delta^{13} \mathrm{C}$ and ${ }^{20} \mathrm{Ne}$ (tables $1 \& 3$ ).

\subsubsection{Argon}

Argon isotope ratios $\left({ }^{40} \mathrm{Ar} /{ }^{36} \mathrm{Ar}\right)$ range from 342 to 561 , all showing an excess of radiogenicallyproduced ${ }^{40} \mathrm{Ar}$ relative to the air value of 298.6 (Lee et al., 2006). Argon concentrations $\left({ }^{36} \mathrm{Ar}\right.$ ) range from 7.0 to $262 \times 10^{-9} \mathrm{~cm}^{3} \mathrm{STPcm}^{-3}$, and like Ne concentrations, show a strong correlation with sample maturity as measured by $\delta^{13} \mathrm{C}$ of methane (Fig 4). Argon isotope ratios and concentrations are shown in figure 5 . Whilst samples with the lowest total ${ }^{40} \mathrm{Ar}$ also tend to have low ${ }^{40} \mathrm{Ar} /{ }^{36} \mathrm{Ar}$, the relationship is not clear at higher ${ }^{40} \mathrm{Ar}$ and cannot be explained solely by radiogenic production of ${ }^{40} \mathrm{Ar}$. Oil-associated gases (either exsolved from oil during production or present as a gas cap in the reservoir (Stolper et al., 2017) (A, B), show a different trend to pure gas samples (C-F), with higher ${ }^{40} \mathrm{Ar}$ concentrations.

\subsubsection{Krypton and xenon}

Measured $\mathrm{Kr}$ and $\mathrm{Xe}$ isotope ratios are all indistinguishable from air, and are not discussed here (Torgersen \& Kennedy, 1999). Krypton concentrations $\left[{ }^{84} \mathrm{Kr}\right]$ range from 4.4 to $26.9 \times 10^{-10} \mathrm{~cm}^{3} \mathrm{STPcm}^{-3}$, and xenon concentrations $\left[{ }^{130} \mathrm{Xe}\right.$ ] range from 1.4 to $7.5 \times 10^{-11} \mathrm{~cm}^{3} \mathrm{STPcm}^{-3}$. Like $\mathrm{Ne}$ and $\mathrm{Ar}$ concentrations, $\mathrm{Kr}$ and $\mathrm{Xe}$ show some correlation with sample maturity. However, samples A1 and A2, from the least mature site, both show appreciably lower $\mathrm{Kr}$ and $\mathrm{Xe}$ than some other samples, making the exact relationship with maturity unclear, and indicating that the heavy noble gases are not affected by maturity in the same way as Ne and Ar, likely due to their already high-content in the sediments themselves (Podosek et al., 1980, 1981).

\section{Discussion}

\subsection{Atmosphere-derived noble gases}

The atmosphere-derived noble gases (ANG) are dominantly sourced from air $\left({ }^{20} \mathrm{Ne},{ }^{36} \mathrm{Ar},{ }^{84} \mathrm{Kr},{ }^{130} \mathrm{Xe}\right)$, and have no significant radiogenic production, primordial or cosmogenic sources (Ballentine et al., 2002; Prinzhofer, 2013; Byrne et al., 2017). These isotopes are introduced into hydrocarbon reservoirs by recharge of air-saturated water (ASW) (Aeschbach-Hertig et al., 2000; Kipfer et al., 2002), and its subsequent interaction with different hydrocarbon phases. Due to the variable solubility of the elements in different fluid phases, variations in the ratios between these isotopes $\left({ }^{20} \mathrm{Ne} /{ }^{36} \mathrm{Ar},{ }^{84} \mathrm{Kr} /{ }^{36} \mathrm{Ar},{ }^{130} \mathrm{Xe} /{ }^{36} \mathrm{Ar}\right)$ can be used to interpret the history of multi-component (i.e., water-gas-oil) interactions within a given hydrocarbon system (Bosch \& Mazor, 1988; Zaikowski \& Spangler, 1990; Ballentine et al., 1991; 1996; 2002; Barry et al., 2016). 
with a high gas-water volume ratio. However, the lower maturity oil-associated gases show fractionated ${ }^{20} \mathrm{Ne} /{ }^{36} \mathrm{Ar}$ of $0.017-0.10$. We interpret this to represent partitioning between oil and gas phases, which is investigated further in appendix $\mathrm{A} .{ }^{84} \mathrm{Kr} /{ }^{36} \mathrm{Ar}$ ranges from 7.0 to $68.9 \times 10^{-3}\left(\mathrm{ASW}=40 \times 10^{-3}\right)$, and ${ }^{130} \mathrm{Xe} /{ }^{36} \mathrm{Ar}$ ranges from 1.39 to $20.7 \times 10^{-4}\left(\mathrm{ASW}=4.14 \times 10^{-4}\right) \cdot{ }^{84} \mathrm{Kr} /{ }^{36} \mathrm{Ar}$ and ${ }^{130} \mathrm{Xe} /{ }^{36} \mathrm{Ar}$ show a more equivocal relationship with maturity, again suggesting that the heavy noble gases are affected differently by maturity variations. All samples except those from the lowest maturity area (A1, A2) show significant excesses of $\mathrm{Kr}$ and Xe compared to ASW, whilst the A samples have depleted $\mathrm{Kr}$ and $\mathrm{Xe}$. It is possible that due to their low maturity, there is still enough of an oil-phase present in samples $\mathrm{A} 1$ and $\mathrm{A} 2$ that partitioning of $\mathrm{Kr}$ and $\mathrm{Xe}$ into the oil phase has resulted in a residually depleted gas, although this is difficult to confirm. There also appears to be no clear relationship within the higher ${ }^{84} \mathrm{Kr} /{ }^{36} \mathrm{Ar}$ and ${ }^{130} \mathrm{Xe} /{ }^{36} \mathrm{Ar}$ samples.

\subsection{Methane generation and noble gas dilution}

The observation that ${ }^{36} \mathrm{Ar}$ concentrations vary by more than an order of magnitude over the range of sample maturities (Fig 4) requires either drastically different hydrogeological regimes across the field, or a previously unrecognized process, innate to the hydrocarbon system, is required to strongly alter ANG concentrations.

We start with the simplifying assumption that the amount of ${ }^{36} \mathrm{Ar}$ delivered from groundwater into the Eagle Ford formation is approximately constant across the basin. This assumption is reasonable unless there is large-scale heterogeneity in the deep-basin groundwater movement over geological timescales. As the Eagle Ford Shale is low-permeability and relatively consistent across the basin, with no significant faulting across the area of interest (Robison, 1997), such heterogeneity would be highly unexpected. Under this assumption, the resultant concentrations in the hydrocarbon phase should be solely affected by the extent of hydrocarbon generation. The resulting reference model presented here shows that the generation of petroleum compounds and secondary cracking of those compounds will both increase the relative amount of hydrocarbon molecules compared to ${ }^{36} \mathrm{Ar}$. This will effectively cause $\left[{ }^{36} \mathrm{Ar}\right]$ to be diluted as hydrocarbon generation and cracking proceeds, and can explain decreasing ${ }^{36} \mathrm{Ar}$ concentrations as a function of increasing maturity. A schematic illustration of this concept is given in figure 6 . In order to eliminate the effects of solubility-dependent fractionation on this process, we normalize $\left[{ }^{36} \mathrm{Ar}\right]$ to $\left[\mathrm{CH}_{4}\right]$ in bulk gas, as both species have similar solubilities at subsurface conditions (Ballentine et al., 1991). Under the assumption that initial ${ }^{36} \mathrm{Ar}$ abundances were approximately uniform across the basin, the resultant $\left[{ }^{36} \mathrm{Ar}\right]$ in the produced methane will be inversely proportional to the amount of methane produced, which can be written symbolically as follows.

$$
\frac{\left[{ }^{36} \mathrm{Ar}\right]}{\left[\mathrm{CH}_{4}\right]} \times F=c
$$
is the amount of methane produced form the source-rock relative to the total potential production $(0 \leq F \leq$ 

associated with methane generation, the extent of methane generation within the basin, and the extent of gas loss from within the source rock. In order to relate the extent of methane production $(F)$ to our observable proxy for maturity, the $\delta^{13} \mathrm{C}$ of the methane, we use a Rayleigh fractionation model (after Rooney et al., 1995). This model assumes that the product (methane) is continuously generated from an initial reservoir (kerogen) with a constant isotopic fractionation. It has been shown to accurately reproduce observed C-isotope ratios in several case studies (see Rooney et al., 1995 for details). We consider two separate end-member scenarios. The first is a fully opensystem case in which the generated methane instantaneously escapes from the source-rock, whereby the methane contained within the source rock has an isotopic composition equal to the methane being produced at that point in the generation process. The second is a fully closed-system model, in which no methane escapes from the source-rock, and the methane that is retained therefore has an isotopic composition equal to the bulk weighted average of the total produced methane that has accumulated. These are referred to as open-system and closed-system models and designated by the subscripts 'o' and 'c' respectively.

$$
\delta^{13} C_{o}=\delta^{13} C_{k}+\varepsilon(1+\ln (1-F))
$$

$$
\delta^{13} C_{c}=\delta^{13} C_{k}-\varepsilon \frac{(1-F) \ln (1-F)}{F}
$$

Where $\delta^{13} \mathrm{C}_{0}, \delta^{13} \mathrm{C}_{\mathrm{c}}$ are the carbon isotope ratios of methane generated in the open and closed-system models respectively, $\delta^{13} C_{k}$ is the initial carbon isotope ratio of the kerogen in the source-rock from which the hydrocarbons are being generated, $\varepsilon$ is the fractionation factor that governs the isotopic fractionation between the parent kerogen and the generated methane, and $\mathrm{F}$ is the fraction of methane produced out of the total potential, again using subscripts ' $\mathrm{o}$ ' and ' $c$ ' to distinguish between open and closed-system cases.

We rearrange equations 2 and 3 to isolate $F$.

$$
F_{o}=1-\exp \left(\frac{\delta^{13} C_{o}-\delta^{13} C_{k}}{\varepsilon}-1\right)
$$

And for the closed system using the substitution $y=\frac{\delta^{13} C_{c}-\delta^{13} C_{k}}{\varepsilon}$ for clarity.

$$
F_{c}=1-\exp \left(\omega\left(\frac{y}{\exp (-y)}\right)-y\right)
$$


By substituting our expressions for $F_{o}$ or $F_{c}$ into equation 1 , we can directly relate the $\delta^{13} \mathrm{C}$ of methane to the $\left[{ }^{36} \mathrm{Ar}\right]$ in the produced gas, in both open and closed-system scenarios. However, we need to constrain $\delta^{13} C_{k}$ and $\varepsilon$, which are both assumed to be constants across the basin. The carbon isotope ratio of the kerogen in the Eagle Ford $\left(\delta^{13} \mathrm{C}_{k}\right)$ is well-constrained, as it has been directly measured in core sections, and although it shows some variation through the section, it averages approximately $\delta^{13} C_{k}=-27 \%$ (Eldrett et al., 2014). The fractionation factor for production of methane from kerogen for any given field is difficult to constrain geochemically, as reservoir conditions and timescales are challenging to recreate in laboratory conditions (Tang et al., 2005). to estimate the $\varepsilon$ parameter. For a given value of $\varepsilon$, we use the observed $\left[{ }^{36} \mathrm{Ar}\right], \delta^{13} \mathrm{C}$, and $\left[\mathrm{CH}_{4}\right]$ from the 10 Eagle Ford samples to calculate 10 values of $c$ using eq. 1, substituting in eq. 4 or 5 for the open and closedsystems respectively. Notably, if a perfect fit to the model were achieved, c would be constant across all data points. A goodness of fit for each trial value of $\varepsilon$ can be taken from the relative variance $\left(\sigma^{2}\right)$ in these calculated c values. Modelling results yield a best fit to the data with $\varepsilon=-20.71 \%$ o $\left(\sigma^{2}=4.1 \%\right)$ for the open-system, and $\varepsilon=-$ $20.72 \%$ o $\left(\sigma^{2}=4.6 \%\right)$ for the closed-system. This is within the range of expected values for $\varepsilon$ reported in previous literature, of -17 to $-25 \%$ (Tang et al., 2000), and effectively indistinguishable for the 2 cases, suggesting that the calculated value for $\varepsilon$ is relatively insensitive to the extent of the system being open or closed. Model curves for both open and closed-system cases are shown in figure 7 alongside the measured data, and both produce a close fit to the data.

The open and closed-system cases do differ in their predictions of the amount of methane generated across the field. The F-values are plotted as a percentage of total potential methane generation along the model curves in figure 7 , and show that the predicted methane generation is consistently higher in the closed system model. We use these two end-member cases to place constraints on the maximum and minimum volumes of methane generated across the field. For the least mature sample (A1), the open-system predicts $1 \%$ of total methane generated, compared to $2 \%$ for the closed system. For the most mature sample (F1), the range is $38-70 \%$ of total methane generated. These results are shown in table 4.

\subsection{Estimation of methane expulsion efficiency from the source-rock} be converted into absolute volumes of generated methane if the generative potential of the kerogen and the organic carbon concentration is known. The total amount of methane generated in the system is calculated as follows:

$$
\left[\mathrm{CH}_{4}\right]_{\text {gen }}=\frac{F \times G \times T O C \times \rho_{S} \times V_{M}}{M_{C H 4}}
$$


Where $\mathrm{F}$ is the fraction of kerogen converted to methane, $\mathrm{G}$ is the generative potential of methane, and TOC is the weight\% of organic carbon in the shale. The shale density $\left(\rho_{s}\right)$, the standard molar volume $\left(V_{M}\right)$ and the molar mass of methane $\left(\mathrm{M}_{\mathrm{CH} 4}\right)$ are used to convert the units from mass of methane per mass of rock to volume of methane per volume of rock. Pitman, 2010, publish RockEval data for the Eagle Ford, and $\mathrm{G}$ can be estimated at approximately 300-350mg of $\mathrm{CH}_{4}$ per $\mathrm{g}$ of kerogen, in close agreement with pyrolysis experiments on other type II shales (Behar et al., 1995). TOC in the Eagle Ford is variable throughout the basin, but across the area of this study is estimated to be 5-6 wt \% (Tian et al., 2013). Using these values alongside our calculated F-value curves from section 5.2 allows us to predict the absolute volume of methane generated with respect to $\delta^{13} \mathrm{C}$ for both open and closed systems. This volume is converted into methane in-place volumes for a range of system 'openness' (expulsion efficiency) by interpolating between F-value curves for the open and closed system and then multiplying again by openness in order to reflect the expulsion of petroleum from the system under such conditions.

$$
\left[\mathrm{CH}_{4}\right]_{\text {in-place }}=\left(\left[\mathrm{CH}_{4}\right]_{\text {gen }}^{\text {closed }}-\Theta\left(\left[\mathrm{CH}_{4}\right]_{\text {gen }}^{\text {closed }}-\left[\mathrm{CH}_{4}\right]_{\text {gen }}^{\text {open }}\right)\right) \times(1-\Theta)
$$

Where $\Theta$ is system openness $(0 \leq \Theta \leq 1)$. It can be seen for that a perfectly closed system $(\Theta=0)$, the amount of methane in-place is equal to that generated under a closed system, and for a perfectly open system $(\Theta=1)$, the amount of methane in-place is zero.

Using the known variability in the above-described parameters, we generate upper and lower-limit curves for $\left[\mathrm{CH}_{4}\right]_{\text {in-place }}$ as a function of $\delta^{13} \mathrm{C}$ for a range of different "system openness". The generated curves are then compared with in-place estimates derived empirically by converting the bulk gas composition to reservoir pressure-temperature conditions. The comparison is shown in figure 8. Due to the convergence at low maturity $\delta^{13} \mathrm{C}$ values it is difficult to distinguish between different levels of system openness, but for the higher maturity samples the predicted vs. observed gas in-place is consistent with approximately $20-40 \%$ openness in the lower generation limit, and $40-60 \%$ in the upper generation limit. This would correspond to $20-40 \%$ of methane expelled in the lower limit scenario, and $40-60 \%$ in the upper limit scenario. Previous estimates of this figure using traditional gas-in-place estimates and hydrocarbon generation models are on the higher end of this range, with Cooles et al. (1986) suggesting a general range of 60-90\% expulsion, Ungerer (1990) proposing $>50 \%$ for mature source-rocks, and more recently Jarvie et al., (2007) calculating a range of $50-70 \%$ for the Barnett Shale. 

time, as daughter products of naturally occurring radioactive elements. The laws governing rates of radioactive decay are well-understood, and production rates can be calculated as a function of the concentrations of the relevant parent isotopes in the surrounding rock. For example, ${ }^{4} \mathrm{He}$ production is dominated by the $\alpha$-decay of ${ }^{235} \mathrm{U},{ }^{238} \mathrm{U}$ and ${ }^{232} \mathrm{Th}$, and the production rate can be calculated using the following equation, after Craig \& Lupton, 1976:

$$
J\left({ }^{4} \mathrm{He}\right)=0.2355 \times 10^{-6} \times[U]\left(1+0.123\left(\frac{[T h]}{[U]}-4\right)\right)
$$
Th are in ppm. Analogous equations for the production of other major radiogenic noble gas species can be found in Ballentine \& Burnard, 2002. The expected concentration of ${ }^{4} \mathrm{He}$ to be produced in-situ can then be calculated using the following equation, after Torgersen, 1980:

$$
\left[{ }^{4} H e\right]_{\text {in-situ }}=\frac{J\left({ }^{4} H e\right) \times \rho t \Lambda \mathrm{R}(1-\varphi)}{\varphi}
$$
from the mineral grains into the surrounding pore-space $(0<\Lambda<1$ and $\Lambda \approx 1$ over geological timescales (Ballentine \& Burnard, 2002)). $R$ is the expansion coefficient from reservoir conditions to atmospheric conditions, needed to account for the dilution of the produced ${ }^{4} \mathrm{He}$ by pressurized $\mathrm{CH}_{4}$ in the pore-space $\left(R=p_{\text {res }} T_{\text {atm }} / p_{\text {atm }} T_{\text {res }}\right)$.

The expected ${ }^{4} \mathrm{He}$ concentrations in the Eagle Ford can be calculated using an average porosity of $9 \%$ (Jennings \& Antia, 2013), average rock density of $2.2 \mathrm{gcm}^{-3}, U$ and Th concentrations of $4 \mathrm{ppm}$ and $6 \mathrm{ppm}$ respectively (Tinnings and Darmaoen, 2016), and a time of 95Myr since the deposition of the Eagle Ford. The expected ${ }^{4} \mathrm{He}$ concentration ranges from $0.95-1.2 \times 10^{-6} \mathrm{~cm}^{3} \mathrm{STPcm}^{-3}$, an order of magnitude lower than the measured values of $1.4-5.3 \times 10^{-5} \mathrm{~cm}^{3} \mathrm{STPcm}^{-3}$ (Table 3). The measured excess of ${ }^{4} \mathrm{He}$ must have been introduced from surrounding rocks, likely exsolving from groundwaters into the gas phase due to the relative insolubility of helium. This suggests there must be an external source of groundwater interaction within the Eagle Ford, despite its low permeability and porosity.

The fact that ${ }^{4} \mathrm{He}$ is so abundant in the samples compared to atmospheric noble gas species indicates that it is nearly $100 \%$ radiogenic, whereas the explicit radiogenic component for $\mathrm{Ar}$ and $\mathrm{Ne}\left({ }^{40} \mathrm{Ar}^{*}\right.$ or $\left.{ }^{21} \mathrm{Ne}^{*}\right)$ must be corrected for atmospheric contributions. This is done by calculating the atmospheric contribution of 

follows:

$$
\left.\left[{ }^{40} \mathrm{Ar}\right]=\left[{ }^{40} \mathrm{Ar}\right]^{*}+\left[{ }^{40} \mathrm{Ar}\right]\right]_{\text {atm }}
$$

391

$$
\left[{ }^{40} A r\right]_{a t m}=\left[{ }^{36} A r\right] \times\left(\frac{{ }^{40} A r}{{ }^{36} A r}\right)_{a i r}
$$

$$
\left[{ }^{40} A r\right] *=\left[{ }^{40} A r\right]-\left[{ }^{36} A r\right] \times\left(\frac{{ }^{40} A r}{{ }^{36} A r}\right)_{\text {air }}
$$
can be used to distinguish in-situ radiogenic production from that introduced by fluid migration. Figure 9 shows a strong correlation between ${ }^{4} \mathrm{He} /{ }^{40} \mathrm{Ar} *$ and ${ }^{21} \mathrm{Ne} *{ }^{40} \mathrm{Ar}$, which is consistent with solubility-dependent fractionation. Predicted solubility-dependent fractionation lines are also shown for in-situ radiogenic production (calculated from U, Th, K, O, and Mg concentrations, Tinnin \& Darmaoen, 2016) and average crustal production ratios. In-situ ${ }^{4} \mathrm{He} /{ }^{40} \mathrm{Ar}^{*}$ and ${ }^{21} \mathrm{Ne}^{*} /{ }^{40} \mathrm{Ar} *$ production ratios are calculated as 17.2 and $9.26 \times 10^{-7}$ respectively, compared to 10.0 and $2.15 \times 10^{-7}$ for average crust (Leya \& Wieler, 1999; Ballentine \& Burnard, 2002). Fractionation lines plot as near straight lines due to the fact that $\mathrm{He}$ and Ne have similar Henry's constants in subsurface conditions (Fernández-Prini et al., 2003). Many of the Eagle Ford samples do not plot close to the in-situ production line, with the average crustal production line providing a better fit, especially for the more highly fractionated, higher maturity samples. This is strong evidence for the influx of externally produced radiogenic isotopes being introduced into the gas phase from groundwater in adjacent sediments. It is clear from these relationships that the Eagle Ford is exhibiting at least partially open system behaviour in a geochemical sense.

\section{Conclusion}

We present high precision noble gas $(\mathrm{He}, \mathrm{Ne}, \mathrm{Ar}, \mathrm{Kr}, \mathrm{Xe})$ isotope and abundance data for 10 natural gas samples produced from the unconventional Eagle Ford shale oil and gas field. By combining these measurements with traditional bulk gas composition and stable isotope data we are able to fully investigate how the noble gas signature changes over the range of different gas compositions produced from the field. This work builds on the relatively few previous noble gas studies to advance our understanding of the physical behaviour of fluids in organic-rich shales and unconventional hydrocarbon systems (Hunt et al., 2012; Darrah et al., 2014, 2015; Wen et al., 2015; Györe et al., 2017; Cao et al., 2018). The samples span a wide range of thermal maturities, as is evident from the bulk fluid composition ranging from oil-associated gas to dry non- 
associated gas, and the $\delta^{13} \mathrm{C}$ of the hydrocarbon compounds have a broad range across the sample suite. The noble gas content of the samples is dominantly radiogenic, with high concentrations of ${ }^{4} \mathrm{He}$ and high ${ }^{40} \mathrm{Ar} /{ }^{36} \mathrm{Ar}$ ratios, and very small amounts of putative mantle helium present in some samples. vary over several orders of magnitude, and are strongly correlated with indicators of gas maturity such as $\delta^{13} \mathrm{C}$. These signatures are explained using a combination of a Rayleigh-fractionation model for methane-generation with $\left[{ }^{36} \mathrm{Ar}\right] /\left[\mathrm{CH}_{4}\right]$ ratios to constrain hydrocarbon generation parameters, including the C-isotope fractionation factor $(\varepsilon=-20.7 \%$ o), and the relative quantities of methane generated across the basin. This approach allows us to determine these crucial parameters using empirical data measured in gas samples produced directly from the reservoir, with the inert behaviour of the noble gases ensuring it is unaffected by extraneous chemical reactions. By comparison with measurements of methane in-place within the source rock, we use this model to constrain the extent of system openness. This allows us to quantify how much methane has been expelled from the source rock (expulsion efficiency), which we estimate to be approximately $40 \%$ for this system. This value is similar to model estimates generated for other source-rocks (Cooles et al., 1986; Jarvie et al., 2007), but the parameters controlling any noble gas variations between systems will require further investigation.

Concentrations of radiogenic ${ }^{4} \mathrm{He}$ are in excess of those that could be produced in-situ over the age of the strata, thus requiring external input from surrounding formations into the shale. Radiogenic ${ }^{4} \mathrm{He} /{ }^{40} \mathrm{Ar} *$ and ${ }^{21} \mathrm{Ne}^{*} /{ }^{40} \mathrm{Ar} *$ reveal significant exchange between the hydrocarbons within the shale and external groundwaters over geological timescales, despite their low porosity and permeability. that the Eagle Ford shale has both expelled significant volumes of hydrocarbons and also acquired radiogenic noble gases from external groundwater. The ability to empirically constrain hydrocarbon volumes expelled may provide significant utility in the construction of basin models designed to understand the evolution of petroleum systems, specifically with regard to primary migration out of the source-rock (Ungerer, 1990). The proliferation of unconventional petroleum exploitation is subject to well-documented environmental concerns over natural gas escape and contamination of the surrounding environment, especially drinking water aquifers. Characterisation of the noble gas signature of these deep shale gases is crucial for the development of techniques designed to identify fugitive gas contamination in these systems (Darrah et al., 2014; Wen et al., 2017). As suggested by Györe et al., 2017, high concentrations of radiogenic ${ }^{4} \mathrm{He}$ may provide evidence to distinguish between younger biogenic gas and older shale gas migrating from depth. The apparent permeability of these sediments to external groundwater influence raises questions over their ability to act as seals for carbon or nuclear waste storage over geological time (Neuzil, 2013; Hendry et al., 2015), although it is possible that the internal generation of hydrocarbons has affected their integrity during burial and thermal maturation (Romero-Sarmiento et al., 2013). 

(NERC) Centre for Doctoral Training in Oil \& Gas, and is sponsored fully by NERC, whose support is gratefully acknowledged. We are grateful to ExxonMobil and XTO Energy for access to samples and associated data, and permission to publish data measured from said samples. We would also like to thank Erdem Idiz for thoughtful discussions on data and modelling.

\section{References}

Aeschbach-Hertig W., Peeters F., Beyerle U. and Kipfer R. (2000) Palaeotemperature reconstruction from noble gases in ground water taking into account equilibration with entrapped air. Nature 405, 1040-1044.

Ballentine C. J., Burgess R. and Marty B. (2002) Tracing Fluid Origin, Transport and Interaction in the Crust. Reviews in Mineralogy and Geochemistry 47, 539-614.

Ballentine C. J. and Burnard P. G. (2002) Production, Release and Transport of Noble Gases in the Continental Crust. Reviews in Mineralogy and Geochemistry 47, 481-538.

Ballentine C. J., O’Nions R. K. and Coleman M. L. (1996) A Magnus opus: Helium, neon, and argon isotopes in a North Sea oilfield. Geochimica et Cosmochimica Acta 60, 831-849.

Ballentine C. J., O’Nions R. K., Oxburgh E. R., Horvath F. and Deak J. (1991) Rare gas constraints on hydrocarbon accumulation, crustal degassing and groundwater flow in the Pannonian Basin. Earth and Planetary Science Letters 105, 229-246.

Barry P. H., Hilton D. R., Füri E., Halldórsson S. A. and Grönvold K. (2014) Carbon isotope and abundance systematics of Icelandic geothermal gases, fluids and subglacial basalts with implications for mantle plume-related CO2 fluxes. Geochimica et Cosmochimica Acta 134, 74-99.

Barry, P.H., Kulongoski, J.T., Landon, M.K., Tyne, R.L., Gillespie, J.M., M.J. Stephens, Hillegonds, D.J., Byrne, D.J., Ballentine, C.J. (2018) Tracing enhanced oil recovery signatures in casing gases using noble gases. Earth and Planetary Science Letters, 496, 57 67.

Barry P. H., Lawson M., Meurer W. P., Danabalan D., Byrne D. J., Mabry J. C. and Ballentine C. J. (2017) Determining fluid migration and isolation times in multiphase crustal domains using noble gases. Geology 45, 775-778.

Barry P. H., Lawson M., Meurer W. P., Warr O., Mabry J. C., Byrne D. J. and Ballentine C. J. (2016) Noble gases solubility models of hydrocarbon charge mechanism in the Sleipner Vest gas field. Geochimica et Cosmochimica Acta 194, 291-309.

Behar F., Vandenbroucke M., Tang Y., Marquis F. and Espitalie J. (1997) Thermal cracking of kerogen in open and closed systems: determination of kinetic parameters and stoichiometric coefficients for oil and gas generation. Organic Geochemistry 26, 321-339.

Bernard B. B., Brooks J. M. and Sackett W. M. (1976) Natural gas seepage in the Gulf of Mexico. Earth and Planetary Science Letters 31, 48-54.

Bernard S. and Horsfield B. (2014) Thermal Maturation of Gas Shale Systems. Annual Review of Earth and Planetary Sciences 42, 635-651. 
Bosch A. and Mazor E. (1988) Natural gas association with water and oil as depicted by atmospheric noble gases: case studies from the southeastern Mediterranean Coastal Plain. Earth and Planetary Science Letters 87, 338-346.

Burnard P., Zimmermann L. and Sano Y. (2013) The Noble Gases as Geochemical Tracers: History and Background. In The Noble Gases as Geochemical Tracers (ed. P. Burnard). Advances in Isotope Geochemistry. Springer Berlin Heidelberg. pp. 1-15.

Byrne D. J., Barry P. H., Lawson M. and Ballentine C. J. (2017) Noble gases in conventional and unconventional petroleum systems. Geological Society, London, Special Publications 468, SP468.5.

Cao C., Zhang M., Tang Q., Yang Y., Lv Z., Zhang T., Chen C., Yang H. and Li L. (2018) Noble gas isotopic variations and geological implication of Longmaxi shale gas in Sichuan Basin, China. Marine and Petroleum Geology 89, 38-46.

Clarke P. R., Portis D. H., Barzola G. J., Bello H. and Basu N. K. (2016) Assessing Well Performance in a Prolific Liquids-rich Shale Play_An Eagle Ford Case Study. In The Eagle Ford Shale (ed. J. Breyer). American Association of Petroleum Geologists. pp. 213-240.

Clarkson C. R., Jensen J. L. and Chipperfield S. (2012) Unconventional gas reservoir evaluation: What do we have to consider? Journal of Natural Gas Science and Engineering 8, 9-33.

Clayton C. (1991) Carbon isotope fractionation during natural gas generation from kerogen. Marine and Petroleum Geology 8, 232-240.

Cooles G. P., Mackenzie A. S. and Quigley T. M. (1986) Calculation of petroleum masses generated and expelled from source rocks. Organic Geochemistry 10, 235-245.

Crovetto R., Fernández-Prini R. and Japas M. L. (1982) Solubilities of inert gases and methane in $\mathrm{H} 2 \mathrm{O}$ and in $\mathrm{D} 2 \mathrm{O}$ in the temperature range of 300 to $600 \mathrm{~K}$. The Journal of Chemical Physics 76, 1077-1086.

Curtis J. B. (2002) Fractured shale-gas systems. AAPG bulletin 86, 1921-1938.

Darrah T. H., Vengosh A., Jackson R. B., Warner N. R. and Poreda R. J. (2014) Noble gases identify the mechanisms of fugitive gas contamination in drinking-water wells overlying the Marcellus and Barnett Shales. Proceedings of the National Academy of Sciences of the United States of America 111, 14076-81.

Day J. M. D., Barry P. H., Hilton D. R., Burgess R., Pearson D. G. and Taylor L. A. (2015) The helium flux from the continents and ubiquity of low-3He/4He recycled crust and lithosphere. Geochimica et Cosmochimica Acta 153, 116-133.

Donovan A. D., Staerker T. S., Gardner R., Pope M. C., Pramudito A. and Wehner M. (2016) Findings from the Eagle Ford Outcrops of West Texas and Implications to the Subsurface of South Texas. In The Eagle Ford Shale (ed. J. Breyer). American Association of Petroleum Geologists. pp. 301-336.

Edman J. D. and Pitman J. K. (2010) Geochemistry of Eagle Ford Group source rocks and oils from the First Shot field area, Texas. Gulf Coast Association of Geological Societies Transactions 60, 217-234. 
Eldrett J. S., Minisini D. and Bergman S. C. (2014) Decoupling of the carbon cycle during Ocean Anoxic Event 2. Geology 42, 567-570.

Fernández-Prini R., Alvarez J. L. and Harvey A. H. (2003) Henry’s Constants and VaporLiquid Distribution Constants for Gaseous Solutes in H2O and D2O at High Temperatures. Journal of Physical and Chemical Reference Data 32, 903-916.

Gautheron C. and Moreira M. (2002) Helium signature of the subcontinental lithospheric mantle. Earth and Planetary Science Letters 199, 39-47.

Hendry M. J., Solomon D. K., Person M., Wassenaar L. I., Gardner W. P., Clark I. D., Mayer K. U., Kunimaru T., Nakata K. and Hasegawa T. (2015) Can argillaceous formations isolate nuclear waste? Insights from isotopic, noble gas, and geochemical profiles. Geofluids 15, $381-386$.

Holland G. and Gilfillan S. M. V. (2013) Application of Noble Gases to the Viability of CO2 storage. In The Noble Gases as Geochemical Tracers Springer.

Hooker P. J., O’Nions R. K. and Oxburgh E. R. (1985) Helium isotopes in North Sea gas fields and the Rhine rift. Nature 318, 273-275.

Hunt A. G., Darrah T. H. and Poreda R. J. (2012) Determining the source and genetic fingerprint of natural gases using noble gas geochemistry: A northern Appalachian Basin case study. AAPG Bulletin 96, 1785-1811.

Jarvie D. M., Hill R. J., Ruble T. E. and Pollastro R. M. (2007) Unconventional shale-gas systems: The Mississippian Barnett Shale of north-central Texas as one model for thermogenic shale-gas assessment. AAPG Bulletin 91, 475-499.

Kennedy B. M., Hiyagon H. and Reynolds J. H. (1990) Crustal neon: a striking uniformity. Earth and Planetary Science Letters 98, 277-286.

Kharaka Y. K. and Specht D. J. (1988) The solubility of noble gases in crude oil at 25$100^{\circ} \mathrm{C}$. Applied Geochemistry 3, 137-144.

Kipfer R., Aeschbach-Hertig W., Peeters F. and Stute M. (2002) Noble Gases in Lakes and Ground Waters. Reviews in Mineralogy and Geochemistry 47, 615-700.

Lee J.-Y., Marti K., Severinghaus J. P., Kawamura K., Yoo H.-S., Lee J. B. and Kim J. S. (2006) A redetermination of the isotopic abundances of atmospheric Ar. Geochimica et Cosmochimica Acta 70, 4507-4512.

Lewan M. D. (1993) Laboratory Simulation of Petroleum Formation. In Organic Geochemistry (eds. M. H. Engel and S. A. Macko). Topics in Geobiology. Springer US. pp. 419-442.

Leya I. and Wieler R. (1999) Nucleogenic production of Ne isotopes in Earth's crust and upper mantle induced by alpha particles from the decay of U and Th. J. Geophys. Res. 104, $15439-15450$.

Lorant F., Prinzhofer A., Behar F. and Huc A.-Y. (1998) Carbon isotopic and molecular constraints on the formation and the expulsion of thermogenic hydrocarbon gases. Chemical Geology 147, 249-264. 
Marty B., Torgersen T., Meynier V., O’Nions R. K. and de Marsily G. (1993) Helium isotope fluxes and groundwater ages in the Dogger Aquifer, Paris Basin. Water Resour. Res. 29, 1025-1035.

McGlade C., Speirs J. and Sorrell S. (2013) Methods of estimating shale gas resources Comparison, evaluation and implications. Energy 59, 116-125.

Neuzil C. E. (2013) Can Shale Safely Host U.S. Nuclear Waste? Eos Trans. AGU 94, 261262.

Neuzil C. E. (1994) How permeable are clays and shales? Water Resour. Res. 30, 145-150.

Niedermann S., Graf T. and Marti K. (1993) Mass spectrometric identification of cosmic-rayproduced neon in terrestrial rocks with multiple neon components. Earth and Planetary Science Letters 118, 65-73.

Ozima M. and Podosek F. A. (2002) Noble gas geochemistry., Cambridge University Press.

Podosek F. A., Bernatowicz T. J. and Kramer F. E. (1981) Adsorption of xenon and krypton on shales. Geochimica et Cosmochimica Acta 45, 2401-2415.

Podosek F. A., Honda M. and Ozima M. (1980) Sedimentary noble gases. Geochimica et Cosmochimica Acta 44, 1875-1884.

Porcelli D., Ballentine C. J. and Wieler R. (2002) An Overview of Noble Gas Geochemistry and Cosmochemistry. Reviews in Mineralogy and Geochemistry 47, 1-19.

Prinzhofer A. (2013) Noble Gases in Oil and Gas Accumulations. In The Noble Gases as Geochemical Tracers (ed. P. Burnard). Advances in Isotope Geochemistry. Springer Berlin Heidelberg. pp. 225-247.

Robison C. R. (1997) Hydrocarbon source rock variability within the Austin Chalk and Eagle Ford Shale (Upper Cretaceous), East Texas, U.S.A. International Journal of Coal Geology 34, 287-305.

Romero-Sarmiento M.-F., Ducros M., Carpentier B., Lorant F., Cacas M.-C., Pegaz-Fiornet S., Wolf S., Rohais S. and Moretti I. (2013) Quantitative evaluation of TOC, organic porosity and gas retention distribution in a gas shale play using petroleum system modeling: Application to the Mississippian Barnett Shale. Marine and Petroleum Geology 45, 315-330.

Rooney M. A., Claypool G. E. and Moses Chung H. (1995) Modeling thermogenic gas generation using carbon isotope ratios of natural gas hydrocarbons. Chemical Geology 126, 219-232.

Schmoker J. W. (2002) Resource-assessment perspectives for unconventional gas systems. AAPG Bulletin 86, 1993-1999.

Schoell M. (1980) The hydrogen and carbon isotopic composition of methane from natural gases of various origins. Geochimica et Cosmochimica Acta 44, 649-661.

Smith S. P. and Kennedy B. M. (1983) The solubility of noble gases in water and in $\mathrm{NaCl}$ brine. Geochimica et Cosmochimica Acta 47, 503-515. 
Stolper D. A., Lawson M., Formolo M. J., Davis C. L., Douglas P. M. J. and Eiler J. M. (2017) The utility of methane clumped isotopes to constrain the origins of methane in natural gas accumulations. Geological Society, London, Special Publications 468, SP468.3.

Tang Y., Huang Y., Ellis G. S., Wang Y., Kralert P. G., Gillaizeau B., Ma Q. and Hwang R. (2005) A kinetic model for thermally induced hydrogen and carbon isotope fractionation of individual n-alkanes in crude oil. Geochimica et Cosmochimica Acta 69, 4505-4520.

Tang Y., Perry J. K., Jenden P. D. and Schoell M. (2000) Mathematical modeling of stable carbon isotope ratios in natural gases $\uparrow$. Geochimica et Cosmochimica Acta 64, 2673-2687.

Tian Y., Ayers W. and D. Jr. McCain W. (2013) The Eagle Ford Shale Play South Texas: Regional Variations in Fluid Types Hydrocarbon Production and Reservoir Properties.

Tinnin B. M. and Darmaoen S. T. R. (2016) Chemostratigraphic Variability of the Eagle Ford Shale, South Texas: Insights into Paleoredox and Sedimentary Facies Changes. In The Eagle Ford Shale (ed. J. Breyer). American Association of Petroleum Geologists. pp. 259-283.

Tissot B. P. and Welte D. H. (eds ) (1984) Petroleum formation and occurrence.

Tolstikhin I. N., Ballentine C. J., Polyak B. G., Prasolov E. M. and Kikvadze O. E. (2017) The noble gas isotope record of hydrocarbon field formation time scales. Chemical Geology 471, 141-152.

Torgersen T. and Clarke W. B. (1985) Helium accumulation in groundwater, I: An evaluation of sources and the continental flux of crustal $4 \mathrm{He}$ in the Great Artesian Basin, Australia. Geochimica et Cosmochimica Acta 49, 1211-1218.

Torgersen T. and Kennedy B. M. (1999) Air-Xe enrichments in Elk Hills oil field gases: role of water in migration and storage. Earth and Planetary Science Letters 167, 239-253.

Ungerer P. (1990) State of the art of research in kinetic modelling of oil formation and expulsion. Organic Geochemistry 16, 1-25.

Ungerer P., Burrus J., Doligez B., Chenet P. Y. and Bessis F. (1990) Basin Evaluation by Integrated Two-Dimensional Modeling of Heat Transfer, Fluid Flow, Hydrocarbon Generation, and Migration (1). AAPG Bulletin 74, 309-335.

Weiss R. F. (1968) Piggyback sampler for dissolved gas studies on sealed water samples. Deep Sea Research and Oceanographic Abstracts 15, 695-699.

Wen T., Castro M. C., Ellis B. R., Hall C. M. and Lohmann K. C. (2015) Assessing compositional variability and migration of natural gas in the Antrim Shale in the Michigan Basin using noble gas geochemistry. Chemical Geology 417, 356-370.

Wen T., Castro M. C., Nicot J.-P., Hall C. M., Larson T., Mickler P. and Darvari R. (2016) Methane Sources and Migration Mechanisms in Shallow Groundwaters in Parker and Hood Counties, Texas-A Heavy Noble Gas Analysis. Environ. Sci.Technol.

Wen T., Castro M. C., Nicot J.-P., Hall C. M., Pinti D. L., Mickler P., Darvari R. and Larson T. (2017) Characterizing the Noble Gas Isotopic Composition of the Barnett Shale and Strawn Group and Constraining the Source of Stray Gas in the Trinity Aquifer, North-Central Texas. Environmental Science and Technology 51, 6533-6541. 
647 Whiticar M. J. (1994) Correlation of natural gases with their sources. Memoirs-American

648 Association of Petroleum Geologists, 261-261.

649 Zaikowski A. and Spangler R. R. (1990) Noble gas and methane partitioning from ground 650 water: An aid to natural gas exploration and reservoir evaluation. Geology 18, 72-74.

651 Zhou Z. and Ballentine C. J. (2006) 4He dating of groundwater associated with hydrocarbon 652 reservoirs. Chemical Geology 226, 309-327.

653 Zhou Z., Ballentine C. J., Kipfer R., Schoell M. and Thibodeaux S. (2005) Noble gas tracing 654 of groundwater/coalbed methane interaction in the San Juan Basin, USA. Geochimica et 655 Cosmochimica Acta 69, 5413-5428.

656 Zhou Z, Ballentine C.J., Schoell M., Stevens S.H. (2012) Identifying and quantifying natural $657 \mathrm{CO}_{2}$ sequestration processes over geological timescales: The Jackson Dome $\mathrm{CO}_{2}$ Deposit, 658 USA. Geochimica et Cosmochimica Acta 86, 257-275.

659 Zumberge J., Ferworn K. and Brown S. (2012) Isotopic reversal ("rollover") in shale gases 660 produced from the Mississippian Barnett and Fayetteville formations. Marine and Petroleum 661 Geology 31, 43-52.

662 Zumberge J., Illich H. and Waite L. (2016) Petroleum Geochemistry of the Cenomanian663 Turonian Eagle Ford Oils of South Texas. In The Eagle Ford Shale (ed. J. Breyer). American 664 Association of Petroleum Geologists. pp. 135-165.

665

666

667

668

Figures

669 


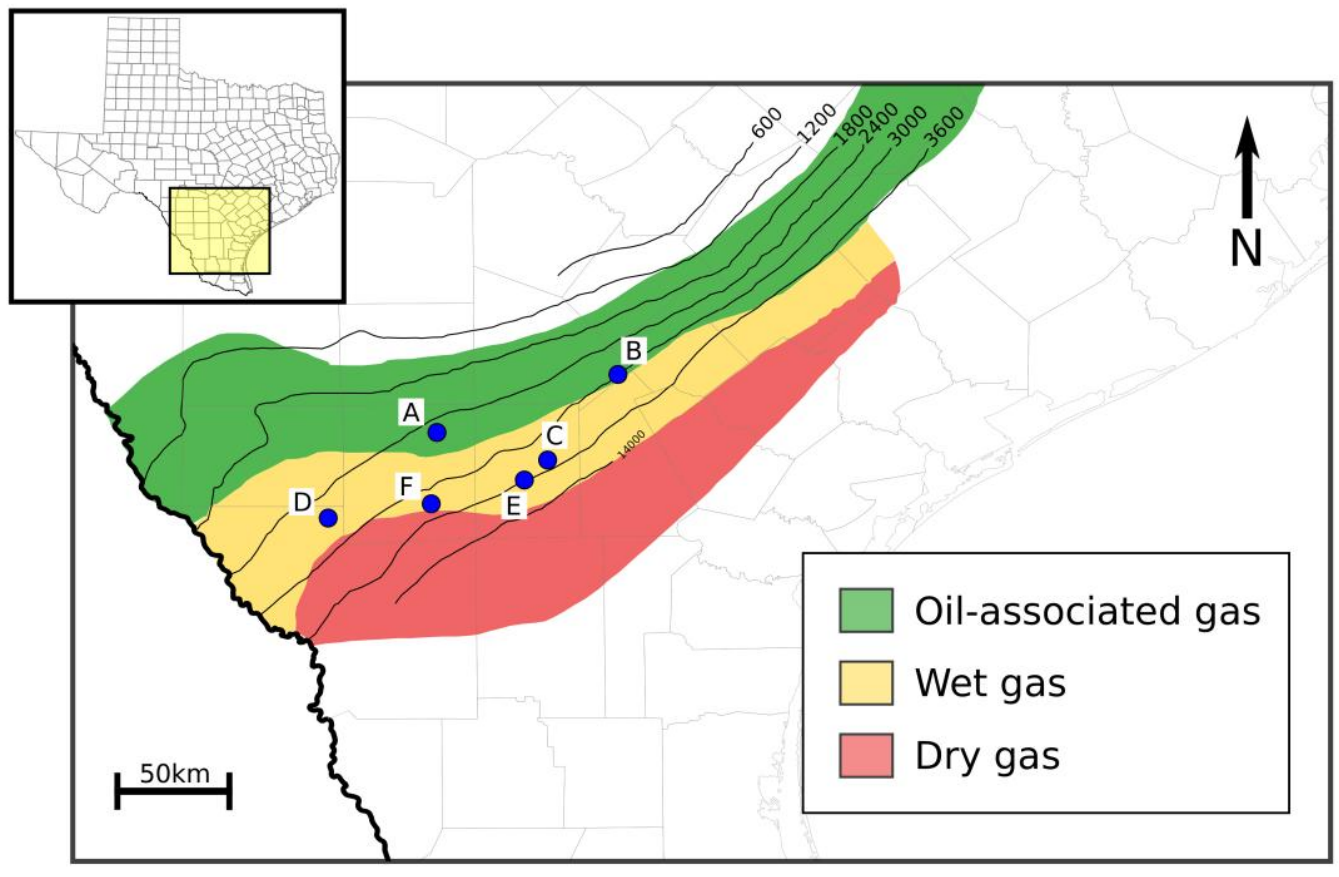

671 Figure 1: Map of the Eagle Ford shale gas play within Texas, showing wellsite locations and ranges of different 672 types of gas production. Contours indicate the depth of the top Eagle Ford shale (m). Adapted from Zumberge 673 et al., 2016).

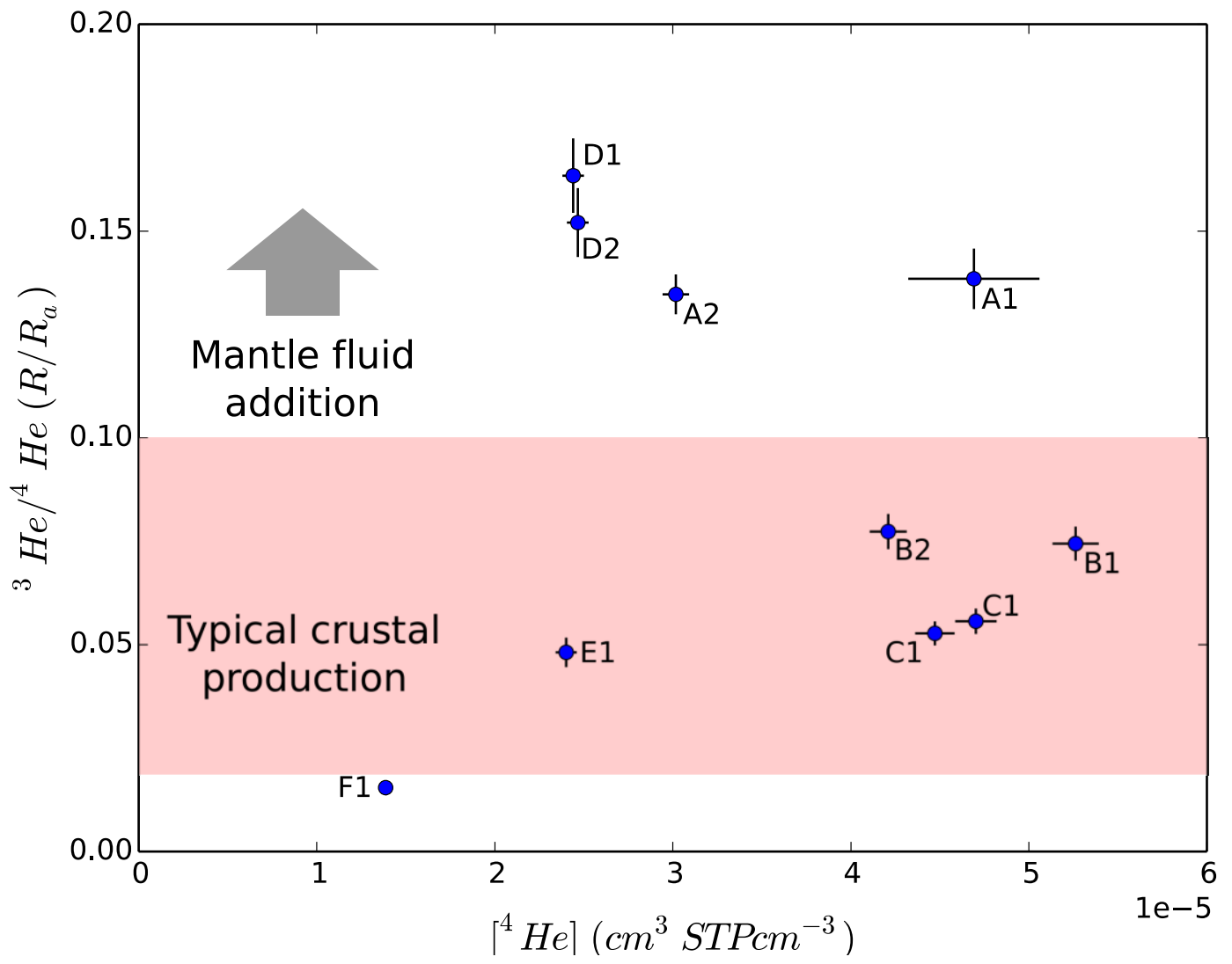




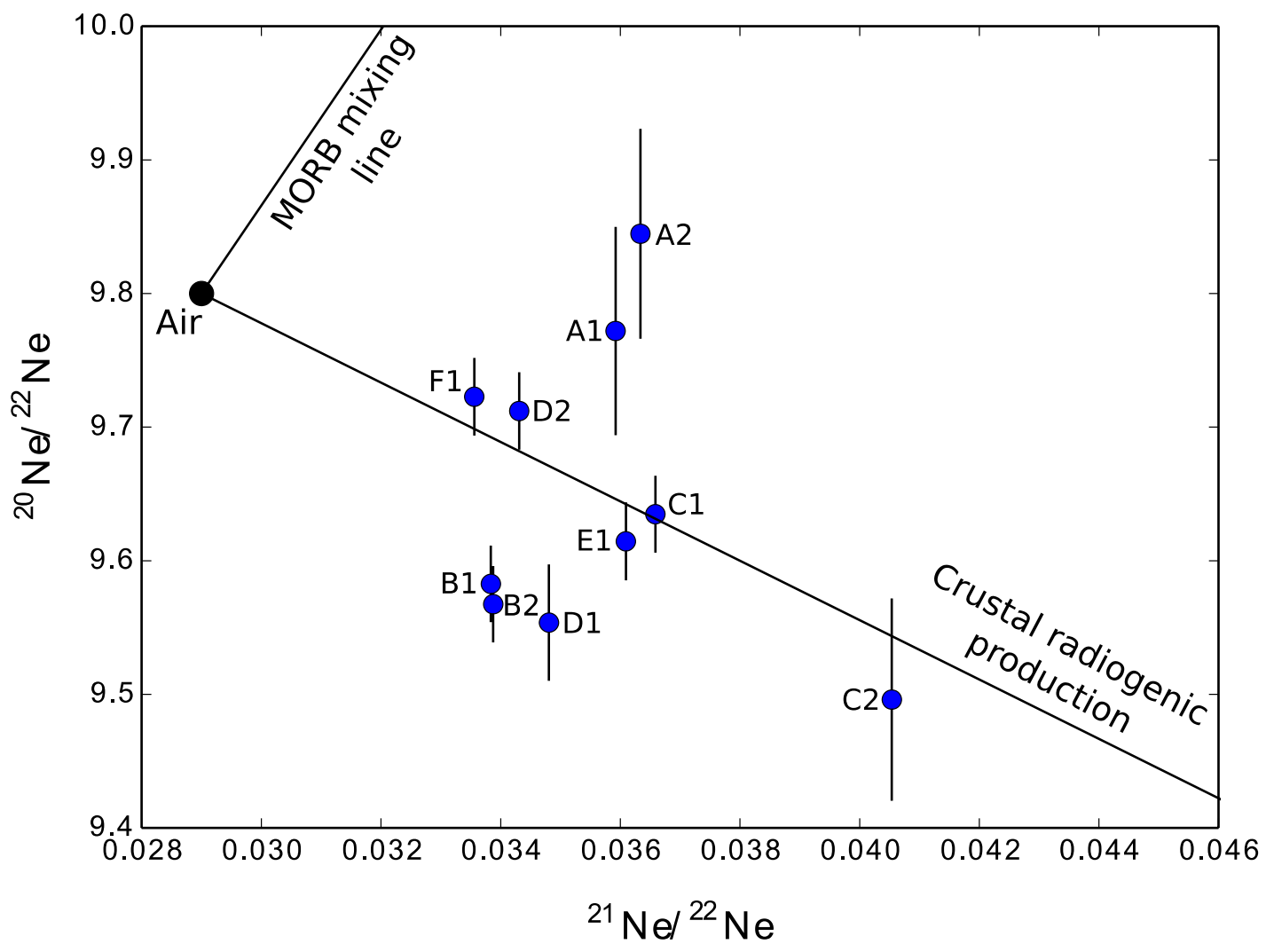

679 Figure 3: Neon isotope plot for the Eagle Ford gases. Typical crustal production ratios are taken from Kennedy et al., 1990, and reflect an empirically observed correlation across a range of crustal fluids. 


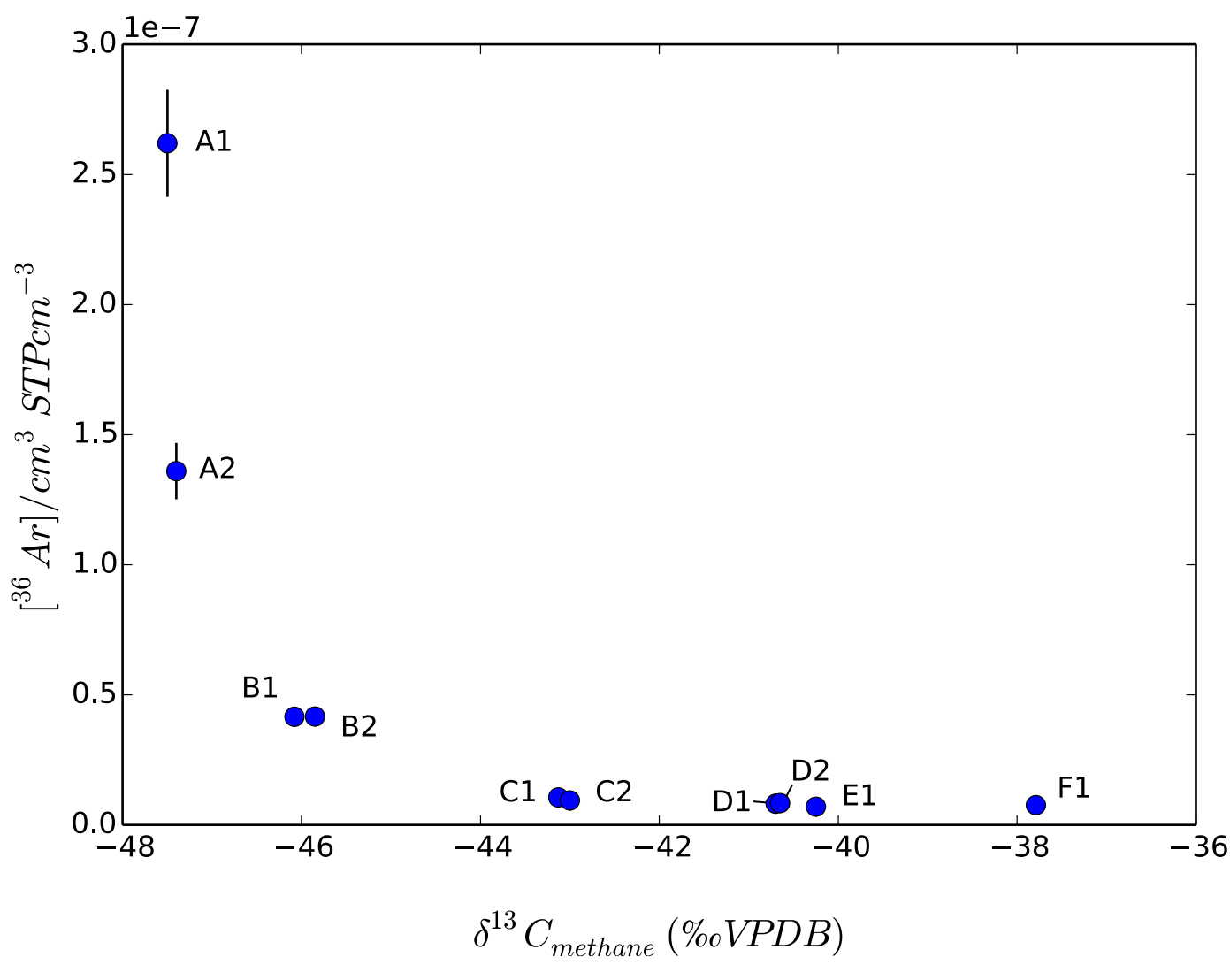

682 Figure 4: Plot illustrating the relationship between ${ }^{36} \mathrm{Ar}$ concentration and $\delta^{13} \mathrm{C}$ of methane, which we consider 683 to be our most reliable indicator of thermal maturity in this system. 


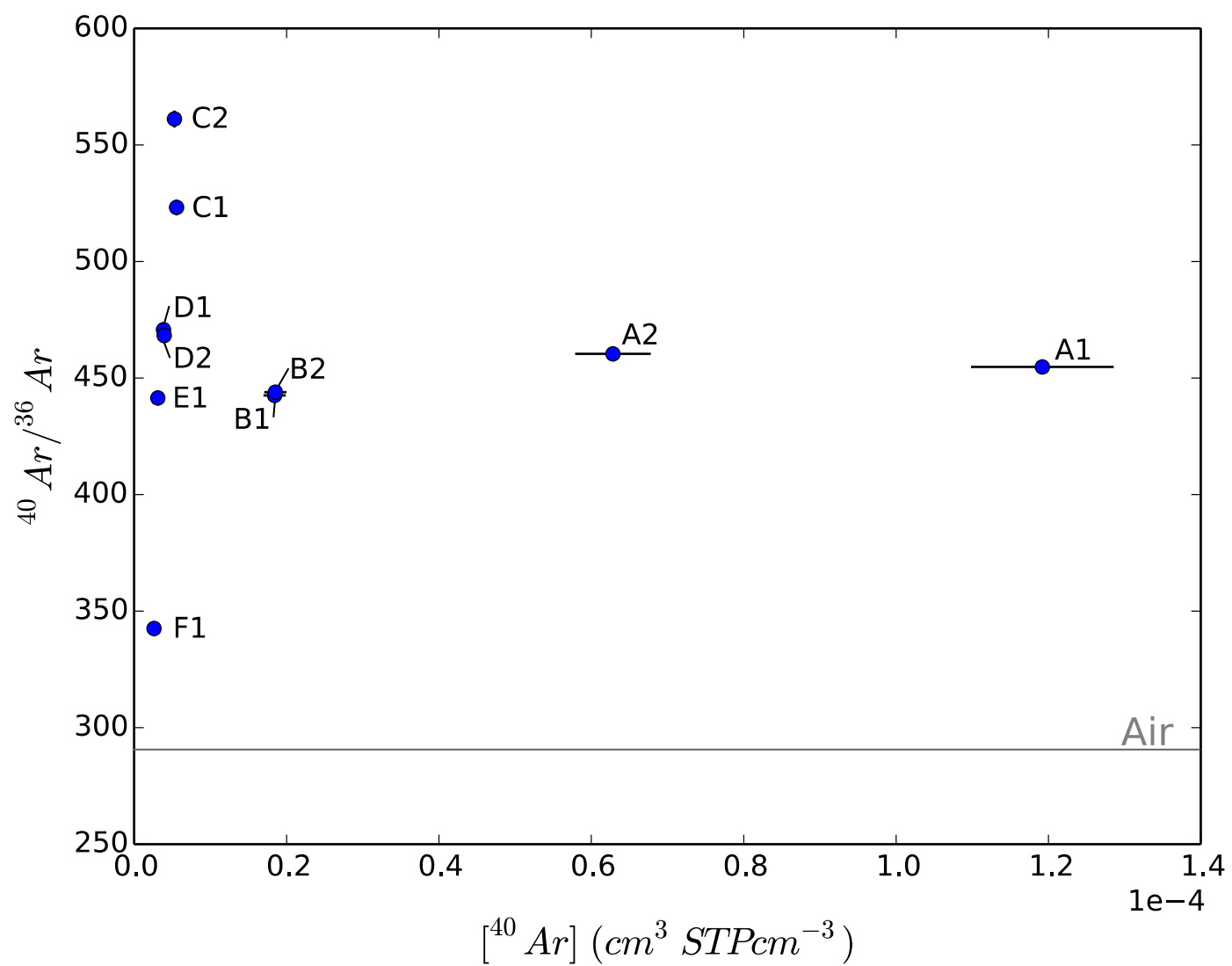

686 Figure 5: Argon concentrations and isotope ratios in the Eagle Ford gases. The isotopic ratio for air is 298.6 687 (Lee et al., 2006). 


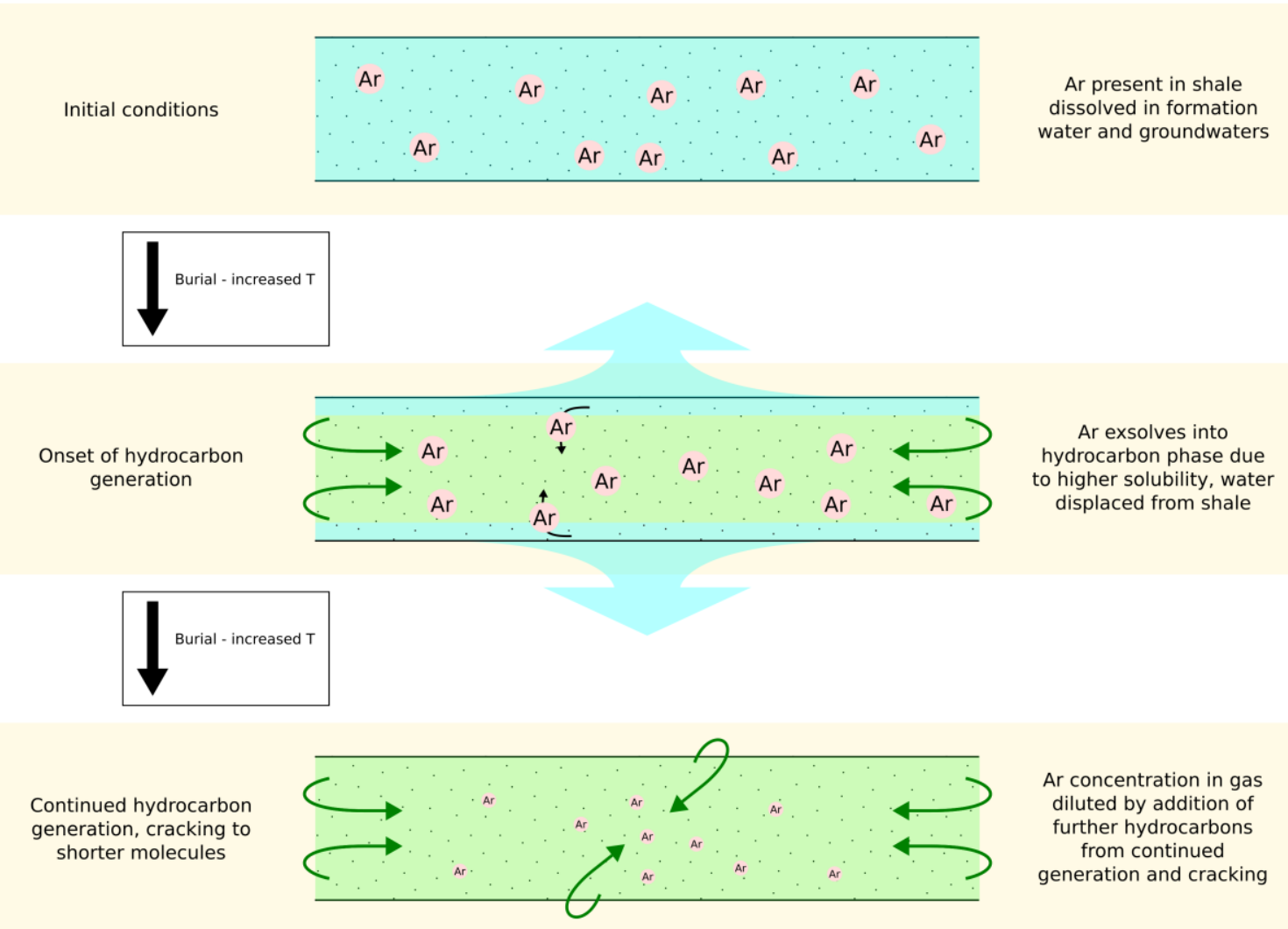

689 Figure 6: Schematic illustration of the Ar dilution model during hydrocarbon generation within the Eagle Ford 690 shale. Argon is expected to follow methane during phase-partitioning in the subsurface, as they have similar 691 solubilities at subsurface PT conditions (Ballentine et al., 1991). Closed system is illustrated in the final stage, 692 whilst an open system would entail partial loss of hydrocarbon phase from the rock, along with equivalent amounts of Ar. 

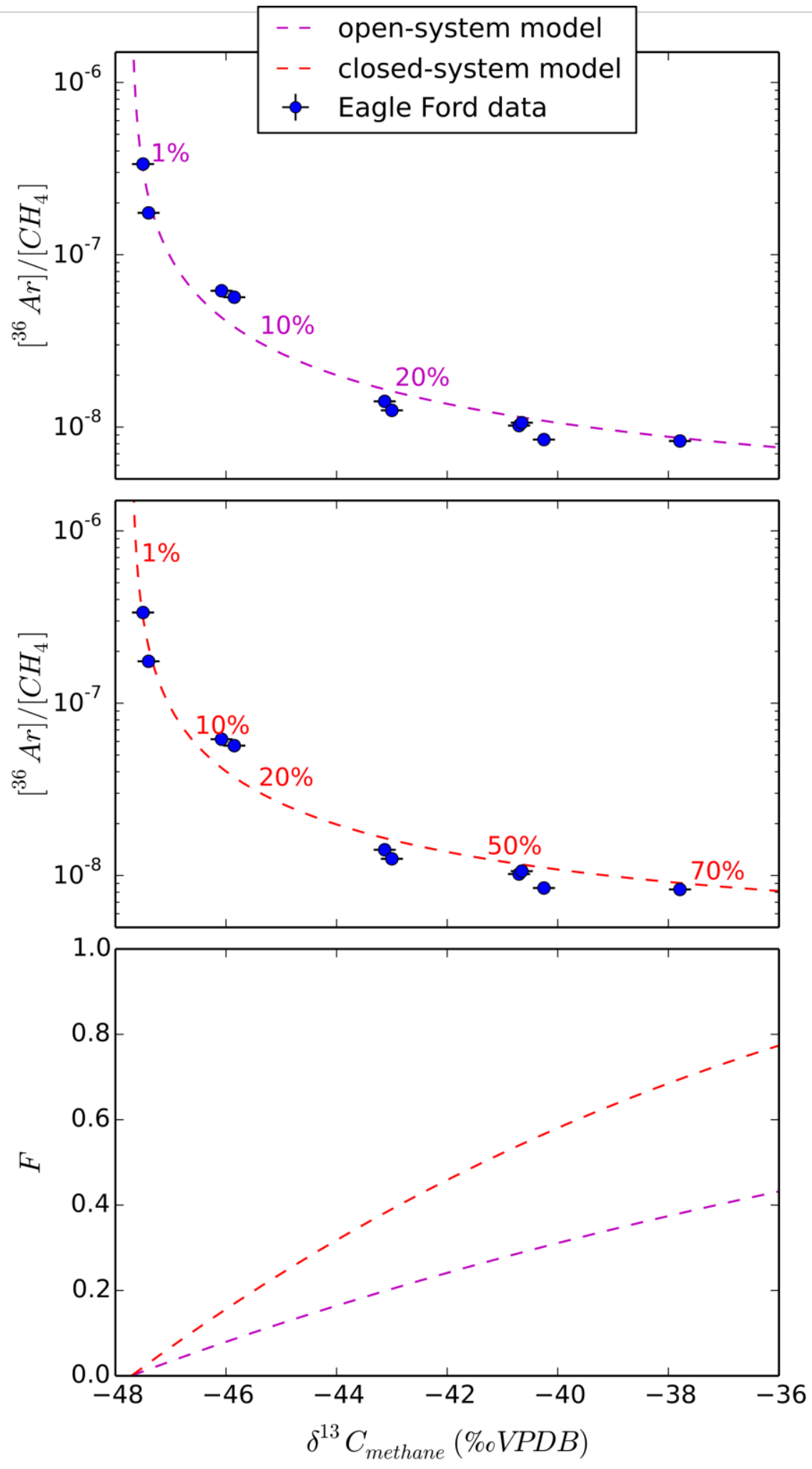

694

695 Figure 7: Results from Ar dilution model, for both open system and closed system calculations. The fraction of methane generated (F) is displayed as a percentage along the 2 curves. Lowermost plot displays the differing predictions for fractional methane generation for open and closed systems. 


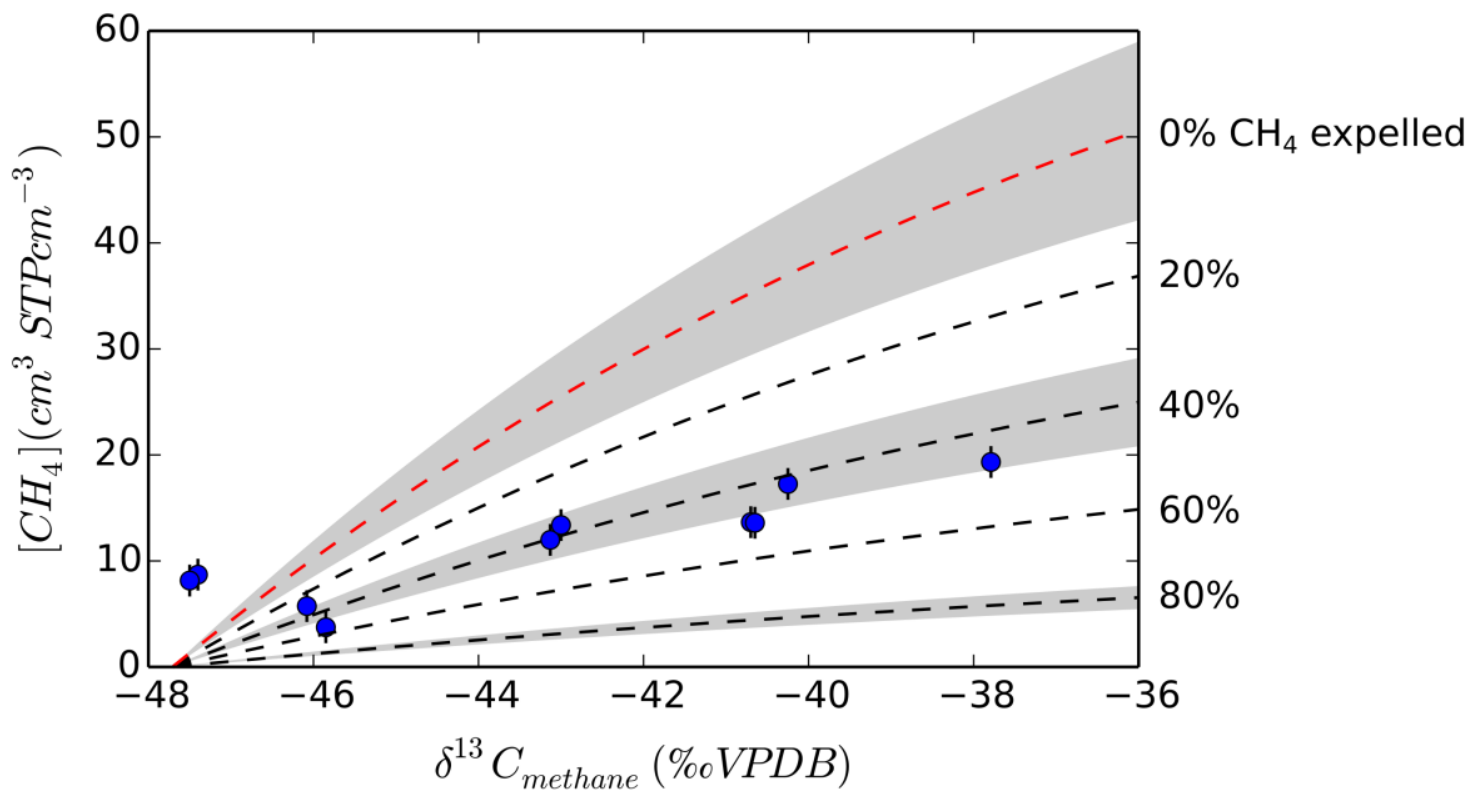

698

699 Figure 8: Predicted evolution of gas in-place within the Eagle Ford Shale alongside data calculated from gas compositions and reservoir PT conditions. Model evolution lines for varying amounts of system openness are displayed according to the percentage of $\mathrm{CH}_{4}$ expelled from the shale. Dashed lines represent the midpoint of the estimates derived from the upper and lower bounds for parameters discussed in section 5.3, whilst shaded areas represent the areas encompassed by the upper and lower bounds (shown for openness of $0 \%, 40 \%$, and $80 \%$ ). Methane concentrations are per volume of rock. 

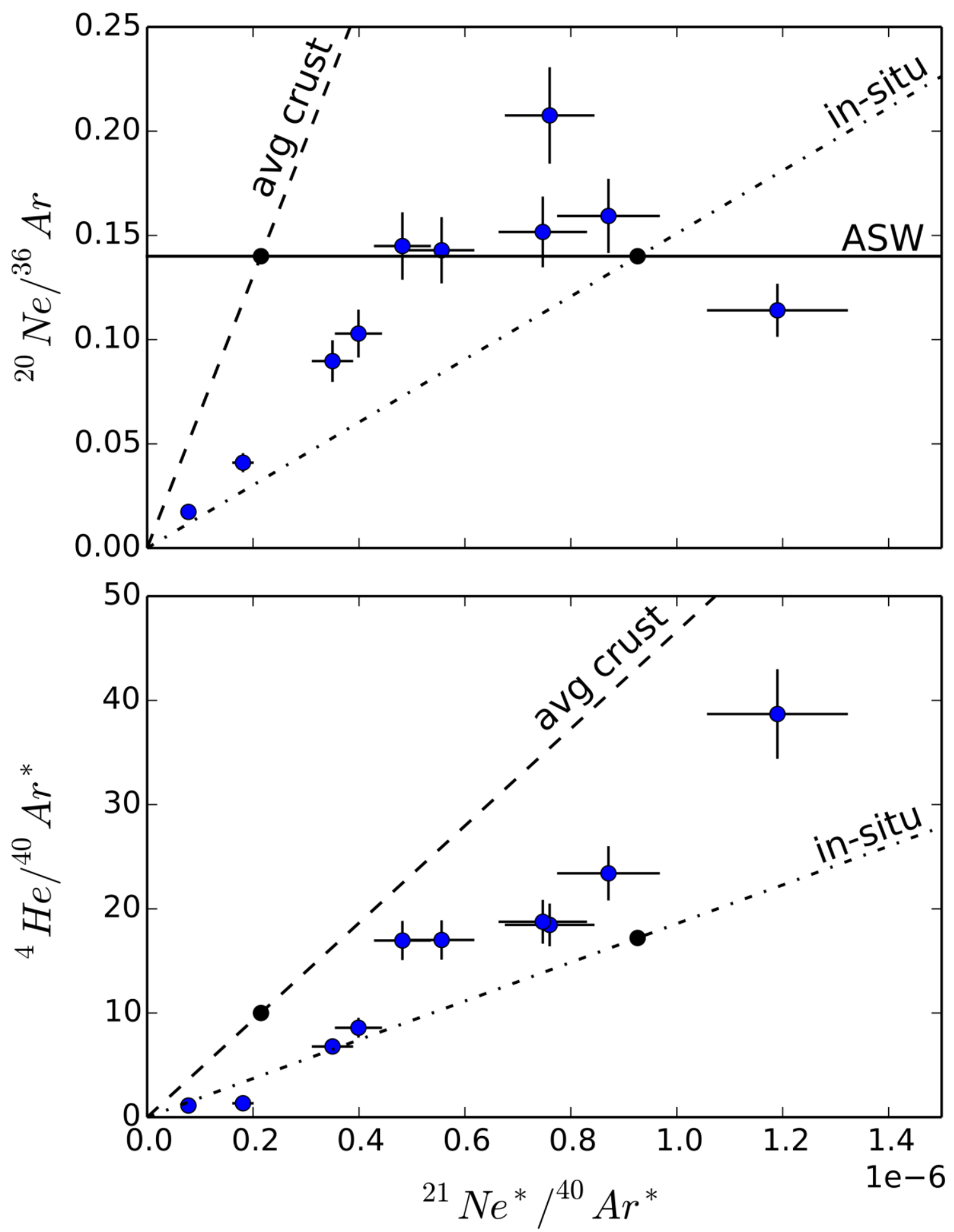

Figure 9: Radiogenic isotope ratios in the Eagle Ford gases. Black points indicate the calculated production ratios for typical crust and within the Eagle Ford shale, and solubility-dependent fractionation lines are drawn through the origin, assuming that $\mathrm{He}$ and Ne have approximately equal solubility under reservoir conditions. Dashed line indicates fractionation from average crust production ratios, and dot-dashed line is that calculated for Eagle Ford in-situ production. 
Table 1: Bulk gas composition and stable isotope data for Eagle Ford gases. Errors are $\pm 0.1 \%$ for concentrations, and $\pm 0.1 \%$ for isotope ratios.

\begin{tabular}{|c|c|c|c|c|c|c|c|c|c|c|c|c|}
\hline \multirow[t]{2}{*}{ Sample } & \multicolumn{6}{|c|}{ Composition (mole\%) } & \multirow[b]{2}{*}{ Gas dryness } & \multicolumn{3}{|c|}{$\delta^{13} \mathrm{C}(\% \circ \mathrm{VPDB})$} & \multirow{2}{*}{$\frac{\delta \mathrm{D}(\% \circ \mathrm{VSMOW})}{\mathrm{C} 1}$} & \multirow[b]{2}{*}{ Well depth $(\mathrm{m})$} \\
\hline & $\mathrm{C} 1$ & $\mathrm{C} 2$ & $\mathrm{C} 3$ & $\mathrm{C} 4+$ & $\mathrm{CO}_{2}$ & $\mathrm{~N}_{2}$ & & $\mathrm{C} 1$ & $\mathrm{C} 2$ & C3 & & \\
\hline $\mathrm{A} 1$ & 78.1 & 12.6 & 5.1 & 2.7 & 1.2 & 0.3 & 4.4 & -47.5 & -32.1 & -29.4 & -261 & 2700 \\
\hline $\mathrm{A} 2$ & 77.8 & 12.6 & 5.3 & 2.7 & 1.3 & 0.3 & 4.3 & -47.4 & -32.2 & -29.3 & -260 & 2700 \\
\hline B1 & 67.4 & 15.8 & 9.6 & 3.9 & 2.1 & 1.0 & 2.7 & -46.1 & -33.5 & -28.8 & -241 & 3120 \\
\hline B2 & 73.7 & 13.9 & 6.7 & 3.4 & 2.0 & 0.4 & 3.6 & -45.9 & -32.5 & -29.3 & -237 & 3100 \\
\hline $\mathrm{C} 1$ & 75.7 & 12.3 & 4.8 & 4.7 & 2.2 & 0.2 & 4.4 & -43.1 & -27.1 & -23.9 & -199 & 3600 \\
\hline $\mathrm{C} 2$ & 75.9 & n.d. & n.d. & n.d. & n.d. & n.d. & n.d. & -43.0 & n.d. & n.d. & n.d. & 3610 \\
\hline D1 & 80.3 & 11.2 & 4.0 & 3.8 & 0.7 & 0.1 & 5.3 & -40.7 & -24.6 & -22.7 & -181 & 2960 \\
\hline D2 & 79.6 & 10.4 & 3.8 & 5.1 & 0.8 & 0.3 & 5.6 & -40.7 & -24.6 & -22.4 & -179 & 2990 \\
\hline E1 & 83.1 & 8.9 & 2.0 & 2.5 & 3.4 & 0.2 & 7.6 & -40.3 & -23.6 & -19.5 & -184 & 3770 \\
\hline F1 & 91.8 & 3.6 & 0.4 & 0.2 & 3.9 & 0.1 & 22.9 & -37.8 & -17.4 & -14.0 & -167 & 3690 \\
\hline
\end{tabular}

713

714 Table 2: Noble gas isotope ratios for Eagle Ford gases. ${ }^{3} \mathrm{He} /{ }^{4} \mathrm{He}$ ratios are reported in units of $\mathrm{R} / \mathrm{R}_{\mathrm{a}}$, where $\mathrm{R}_{\mathrm{a}}$ is the air ratio of $1.4 \times 10^{-6}$ (Porcelli et al., 2002 ).

\begin{tabular}{lrlrrrrrr} 
Sample & ${ }^{3} \mathrm{He} /{ }^{4} \mathrm{He}$ & $\pm 2 \sigma$ & ${ }^{20} \mathrm{Ne} /{ }^{22} \mathrm{Ne}$ & $\pm 2 \sigma$ & ${ }^{21} \mathrm{Ne} /{ }^{22} \mathrm{Ne}$ & $\pm 2 \sigma$ & ${ }^{40} \mathrm{Ar} /{ }^{36} \mathrm{Ar}$ & $\pm 2 \sigma$ \\
\hline A1 & 0.138 & 0.007 & 9.77 & 0.08 & 0.0359 & 0.0001 & 454.8 & 2.9 \\
A2 & 0.135 & 0.005 & 9.84 & 0.08 & 0.0363 & 0.0001 & 460.4 & 3.0 \\
B1 & 0.074 & 0.004 & 9.58 & 0.03 & 0.0338 & 0.0001 & 442.6 & 2.8 \\
B2 & 0.077 & 0.004 & 9.57 & 0.03 & 0.0339 & 0.0001 & 444.0 & 2.9 \\
C1 & 0.053 & 0.003 & 9.63 & 0.03 & 0.0366 & 0.0001 & 523.2 & 3.4 \\
C2 & 0.056 & 0.003 & 9.50 & 0.08 & 0.0405 & 0.0002 & 561.2 & 3.7 \\
D1 & 0.163 & 0.009 & 9.55 & 0.04 & 0.0348 & 0.0001 & 470.8 & 3.1 \\
D2 & 0.152 & 0.008 & 9.71 & 0.03 & 0.0343 & 0.0001 & 468.3 & 3.1 \\
E1 & 0.048 & 0.004 & 9.61 & 0.03 & 0.0361 & 0.0001 & 441.5 & 2.9 \\
F1 & 0.015 & 0.001 & 9.72 & 0.03 & 0.0336 & 0.0001 & 342.5 & 2.2 \\
\hline
\end{tabular}


Table 3: Noble gas concentrations for Eagle Ford gases. Units are $\mathrm{cm}^{3} \mathrm{STPcm}{ }^{-3},{ }^{*}$ indicates the concentration of the radiogenic component corrected for atmospheric 716 content by comparing with non-radiogenically produced isotope.

\begin{tabular}{|c|c|c|c|c|c|c|c|c|c|c|c|c|c|c|}
\hline Sample & $\begin{array}{r}{ }^{20} \mathrm{Ne} \\
\left(\times 10^{-9}\right) \\
\end{array}$ & $\pm 2 \sigma$ & $\begin{array}{r}{ }^{36} \mathrm{Ar} \\
\left(\times 10^{-9}\right) \\
\end{array}$ & $\pm 2 \sigma$ & $\begin{array}{r}{ }^{84} \mathrm{Kr} \\
\left(\times 10^{-10}\right) \\
\end{array}$ & $\pm 2 \sigma$ & $\begin{array}{r}{ }^{130} \mathrm{Xe} \\
\left(\times 10^{-11}\right) \\
\end{array}$ & $\pm 2 \sigma$ & $\begin{array}{r}{ }^{4} \mathrm{He} \\
\left(\times 10^{-5}\right) \\
\end{array}$ & $\pm 2 \sigma$ & $\begin{array}{r}{ }^{21} \mathrm{Ne}^{*} \\
\left(\times 10^{-13}\right) \\
\end{array}$ & $\pm 2 \sigma$ & $\begin{array}{r}{ }^{40} \mathrm{Ar}^{*} \\
\left(\times 10^{-6}\right) \\
\end{array}$ & $\pm 2 \sigma$ \\
\hline A1 & 4.54 & 0.36 & 262.10 & 20.59 & 20.14 & 1.58 & 4.96 & 0.39 & 4.69 & 0.37 & 32.56 & 2.56 & 41.75 & 3.28 \\
\hline $\mathrm{A} 2$ & 5.57 & 0.44 & 136.48 & 10.80 & 9.59 & 0.75 & 1.89 & 0.15 & 3.02 & 0.07 & 40.73 & 3.20 & 22.50 & 1.77 \\
\hline B1 & 4.28 & 0.34 & 41.65 & 3.30 & 26.52 & 2.09 & 7.41 & 0.58 & 5.26 & 0.13 & 24.46 & 1.92 & 6.12 & 0.48 \\
\hline B2 & 3.74 & 0.29 & 41.74 & 3.30 & 26.88 & 2.11 & 7.50 & 0.59 & 4.21 & 0.10 & 21.72 & 1.71 & 6.20 & 0.49 \\
\hline $\mathrm{C} 1$ & 2.20 & 0.17 & 10.63 & 0.84 & 6.15 & 0.48 & 1.77 & 0.14 & 4.47 & 0.11 & 18.40 & 1.45 & 2.42 & 0.19 \\
\hline $\mathrm{C} 2$ & 1.43 & 0.11 & 9.43 & 0.75 & 5.64 & 0.44 & 1.61 & 0.13 & 4.70 & 0.12 & 18.71 & 1.48 & 2.51 & 0.20 \\
\hline D1 & 1.17 & 0.09 & 8.19 & 0.65 & 5.13 & 0.40 & 1.46 & 0.11 & 2.44 & 0.06 & 7.98 & 0.63 & 1.43 & 0.11 \\
\hline D2 & 1.22 & 0.10 & 8.42 & 0.67 & 5.21 & 0.41 & 1.45 & 0.11 & 2.47 & 0.06 & 7.01 & 0.55 & 1.45 & 0.11 \\
\hline E1 & 1.12 & 0.09 & 7.03 & 0.56 & 4.43 & 0.35 & 1.38 & 0.11 & 2.40 & 0.06 & 8.93 & 0.70 & 1.03 & 0.08 \\
\hline F1 & 0.87 & 0.07 & 7.62 & 0.60 & 5.25 & 0.41 & 1.58 & 0.12 & 1.39 & 0.03 & 4.28 & 0.34 & 0.36 & 0.03 \\
\hline
\end{tabular}

Table 4: Model parameter results for extent of methane generation (F) and system openness $(\Theta)$ discussed in sections 5.2 and 5.3 respectively. Values for [ $\mathrm{CH}_{4}$ ] in-place within the reservoir (per rock volume), and model estimates for $\mathrm{CH}_{4}$ expelled, both per rock volume, and total expelled from the shale by area. Model predictions for samples $\mathrm{A} 1$ and $\mathrm{A} 2$ are not presented as they fall outside the predicted model envelope (see Fig 8).

\begin{tabular}{|c|c|c|c|c|c|c|c|}
\hline \multirow[b]{2}{*}{ Sample } & \multicolumn{2}{|c|}{$F$} & \multicolumn{2}{|c|}{$\Theta$} & \multirow{2}{*}{$\begin{array}{c}{\left[\mathrm{CH}_{4}\right]_{\text {in-place }}} \\
\left(\mathrm{cm}^{3} \mathrm{STPcm}^{-3}\right)\end{array}$} & \multicolumn{2}{|c|}{$\left[\mathrm{CH}_{4}\right]_{\text {expelled }}\left(\mathrm{cm}^{3} \mathrm{STPcm}^{-3}\right)$} \\
\hline & open & closed & $\min$ & $\max$ & & $\min$ & $\max$ \\
\hline A1 & 0.01 & 0.02 & n.a. & n.a. & 8.15 & - & - \\
\hline $\mathrm{A} 2$ & 0.02 & 0.03 & n.a. & n.a. & 8.71 & - & - \\
\hline B1 & 0.08 & 0.15 & 0.21 & 0.38 & 5.74 & 1.55 & 3.52 \\
\hline B2 & 0.09 & 0.17 & 0.47 & 0.59 & 3.74 & 3.34 & 5.42 \\
\hline $\mathrm{C} 1$ & 0.20 & 0.38 & 0.32 & 0.47 & 11.99 & 5.62 & 10.58 \\
\hline $\mathrm{C} 2$ & 0.20 & 0.39 & 0.28 & 0.43 & 13.38 & 5.09 & 10.23 \\
\hline D1 & 0.29 & 0.54 & 0.42 & 0.55 & 13.66 & 9.95 & 16.87 \\
\hline D2 & 0.29 & 0.54 & 0.43 & 0.56 & 13.60 & 10.08 & 17.03 \\
\hline E1 & 0.30 & 0.57 & 0.34 & 0.48 & 17.26 & 8.75 & 16.19 \\
\hline F1 & 0.38 & 0.70 & 0.38 & 0.52 & 19.33 & 11.98 & 21.15 \\
\hline
\end{tabular}


Noble gas partitioning between different fluid phases (water, oil, gas) in crustal systems follows Henry-law solubility to close approximation, even at high temperatures (Crovetto et al., 1982). Henry's constants are well constrained for water and oil across a range of temperatures, salinities, and API gravities (Smith \& Kennedy, 1983; Ballentine et al., 2002). Due to their differing solubilities in water and oil, the noble gases have different affinities for water, oil, or gas phases when they contact another phase. Amongst the atmospherically-derived noble gases, neon is the least soluble in both oil and water, with solubility increasing with atomic number up to xenon (Kharaka \& Specht, 1988; Fernández-Prini et al., 2003). Fractionation of ANGs in petroleum systems is often attributed to solubility-dependent partitioning between different fluid phases (i.e., water, oil and gas). Under the assumption that all the ANGs are initially delivered into the subsurface dissolved in ASW, which has a well-defined composition, it is possible to reconstruct the phase-partitioning history of a petroleum system by looking at the ANG composition of a single phase (Zartman et al., 1962; Bosch \& Mazor, 1988; Zaikowski \& Spangler, 1990; Ballentine et al., 1991; 1996; 2002).

A number of different models describe water-gas, water-oil, and oil-gas partitioning in different reservoir geometries for conventional petroleum systems (see Barry et al., 2016 for a comprehensive review). In an unconventional source rock-reservoir, we predict that a simple closed-system water-oil partitioning model is most appropriate, as the porous volume of the shale will initially be filled with ASW, which will interact with an oil phase - formed in the first stages of hydrocarbon generation. As hydrocarbon generation continues, the ratio of oil to water in the system $\left(\mathrm{V}_{\mathrm{o}} / \mathrm{V}_{\mathrm{w}}\right)$ will increase, and the ANG partitioning and concentrations will evolve.

Upon the initial generation of an oil phase $\left(\mathrm{V}_{\mathrm{o}} / \mathrm{V}_{\mathrm{w}} \approx 0\right)$, argon will preferentially partition from the ASW into the oil phase relative to neon, and the oil phase will consequently have a ${ }^{20} \mathrm{Ne} /{ }^{36} \mathrm{Ar}$ lower than the ASW ratio. As oil generation continues and $V_{o} / V_{w}$ increases, more of the noble gases will partition into the oil phase and the ${ }^{20} \mathrm{Ne} /{ }^{36} \mathrm{Ar}$ of the oil phase will increase towards the ASW ratio. When $\mathrm{V}_{\mathrm{o}} / \mathrm{V}_{\mathrm{w}}$ becomes large, effectively $100 \%$ of the noble gases will be partitioned into the oil phase, and the ${ }^{20} \mathrm{Ne} /{ }^{36} \mathrm{Ar}$ of the oil phase will be equal to that of the initial ASW. Concentrations of ${ }^{20} \mathrm{Ne}$ and ${ }^{36} \mathrm{Ar}$ in the oil phase will consistently decrease with increasing $V_{0} / V_{w}$. We can use the following equation to describe the relationship between both ${ }^{20} \mathrm{Ne} /{ }^{36} \mathrm{Ar}$ and $\left[{ }^{36} \mathrm{Ar}\right]$ and $\mathrm{V}_{\mathrm{o}} / \mathrm{V}_{\mathrm{w}}$.

$$
\frac{V_{o}}{V_{w}}=\frac{C_{a s w}^{i}}{C_{o}^{i}}-\frac{K_{o}^{i}}{K_{w}^{i}}
$$
concentrations of noble gas species $i$ in the oil phase and the initial air-saturated water, and $K_{\circ}^{i}$ and $K_{w}^{i}$ are the Henry's constants of noble gas species $i$ in oil and water. Henry's constants are temperature-dependent and 
calculated after Fernández-Prini et al., 2003. ${ }^{36} \mathrm{Ar}$ concentrations can be calculated directly using equation $\mathrm{A} 1$, and ${ }^{20} \mathrm{Ne} /{ }^{36} \mathrm{Ar}$ ratios are simply calculated by comparing the results from equation $\mathrm{A} 1$ for both ${ }^{20} \mathrm{Ne}$ and ${ }^{36} \mathrm{Ar}$.

Figure $\mathrm{A} 1$ shows the modelled evolution of ${ }^{20} \mathrm{Ne} /{ }^{36} \mathrm{Ar}$ and $1 /\left[{ }^{36} \mathrm{Ar}\right]$ with respect to $\mathrm{V}_{\mathrm{o}} / \mathrm{V}_{\mathrm{w}}$ in the hydrocarbon phase for Eagle Ford pressure-temperature conditions, alongside data measured in the Eagle Ford samples. The mature gas samples are consistent with this model, having ${ }^{20} \mathrm{Ne} /{ }^{36} \mathrm{Ar}$ that is effectively indistinguishable from ASW, and concentrations consistent with high $V_{0} / V_{w}$ of 100-300. However, these samples are dry gas rather than oil. In a closed system, the complete cracking of oil to gas would not affect ${ }^{20} \mathrm{Ne} /{ }^{36} \mathrm{Ar}$ of the hydrocarbon phase, but would decrease concentrations as the hydrocarbon phase expanded; this is effectively equivalent to an apparent increase in $V_{o} / V_{w}$ as secondary cracking progresses. However, the oil-water partitioning model clearly does not account for the extent of fractionation observed in the oilassociated gas samples.

The highly fractionated ${ }^{20} \mathrm{Ne} /{ }^{36} \mathrm{Ar}$ exhibited in the lower-maturity samples could be explained by a solubility controlled open-system Rayleigh-fractionation partitioning model between oil and gas phases. Conceptually, this describes the formation and escape of gas bubbles from the oil phase, either because of sufficient cracking of oil compounds to form a free gas phase, or gaseous hydrocarbon compounds coming out of solution in the oil phase due to changes in pressure-temperature conditions. This could happen as a result of geological processes or production effects. The Rayleigh fractionation equation describing open-system gas loss is:

$$
\left(\frac{{ }^{20} N e}{{ }^{36} A r}\right)=\left(\frac{{ }^{20} N e}{{ }^{36} A r}\right)_{0} \times f^{(\alpha-1)}
$$

Where $\left({ }^{20} \mathrm{Ne} /{ }^{36} \mathrm{Ar}\right)$ is the ratio in the oil phase, $\left({ }^{20} \mathrm{Ne} /{ }^{36} \mathrm{Ar}\right)_{0}$ is the initial ratio in the oil phase prior to gas loss, $f$ is the fraction of ${ }^{36} \mathrm{Ar}$ remaining in the oil phase, and $\alpha$ is the fractionation factor (the ratio of the Henry's constants for $\mathrm{Ne}$ and Ar in oil).

The cyan lines on Figure $\mathrm{A} 1$ show the predicted evolution of the ${ }^{20} \mathrm{Ne} /{ }^{36} \mathrm{Ar}$ in the oil phase during open-system gas-oil partitioning. It can be seen that this process can account for the fractionation seen, if $90 \%$ of the argon initially present has been lost from the system.

The applied models are able to qualitatively replicate the observed patterns of $\left[{ }^{36} \mathrm{Ar}\right]$ and ${ }^{20} \mathrm{Ne} /{ }^{36} \mathrm{Ar}$ observed in the Eagle Ford gas, but are likely too simplistic to represent a quantitative description of real processes. Our assumption of a simple closed system with a constant and conserved amount of ${ }^{36} \mathrm{Ar}$ present is inconsistent with observed radiogenic isotope patterns (section 5.4) that show the influx of external groundwater, as well as the predictions from section 5.3 on system openness. The open-system oil-gas partitioning required to explain the fractionated ${ }^{20} \mathrm{Ne} /{ }^{36} \mathrm{Ar}$ ratios observed in the oil-associated gases further requires deviation from this closed system. Furthermore, the processes controlling oil-gas partitioning during 
hydrocarbon cracking and expulsion are likely to be more complex than the simple time-independent system we have presented using a single partitioning parameter. These noble gas partitioning models were developed to describe conventional systems, where hydrocarbons and water are in well-defined separate phases in porous reservoirs, and traps and seals provide a relatively stable closed system (Bosch \& Mazor, 1988; Zaikowski \& Spanlger, 1990; Ballentine et al., 1991; 1996; Barry et al., 2016). We suggest that the low-porosity, more complex phase behaviour, and extensive expulsion and migration make these models difficult to apply directly into unconventional systems.

Figure A.1 Predicted ${ }^{20} \mathrm{Ne} /{ }^{36} \mathrm{Ar}$ and $\left[{ }^{36} \mathrm{Ar}\right]$ evolution lines for solubility-dependent partitioning models, alongside measured data from the Eagle Ford gases. Numbers along oil-water partitioning line signify $V_{o} / V_{w}$ and percentages along cyan line indicate the percentage of argon lost from the system.

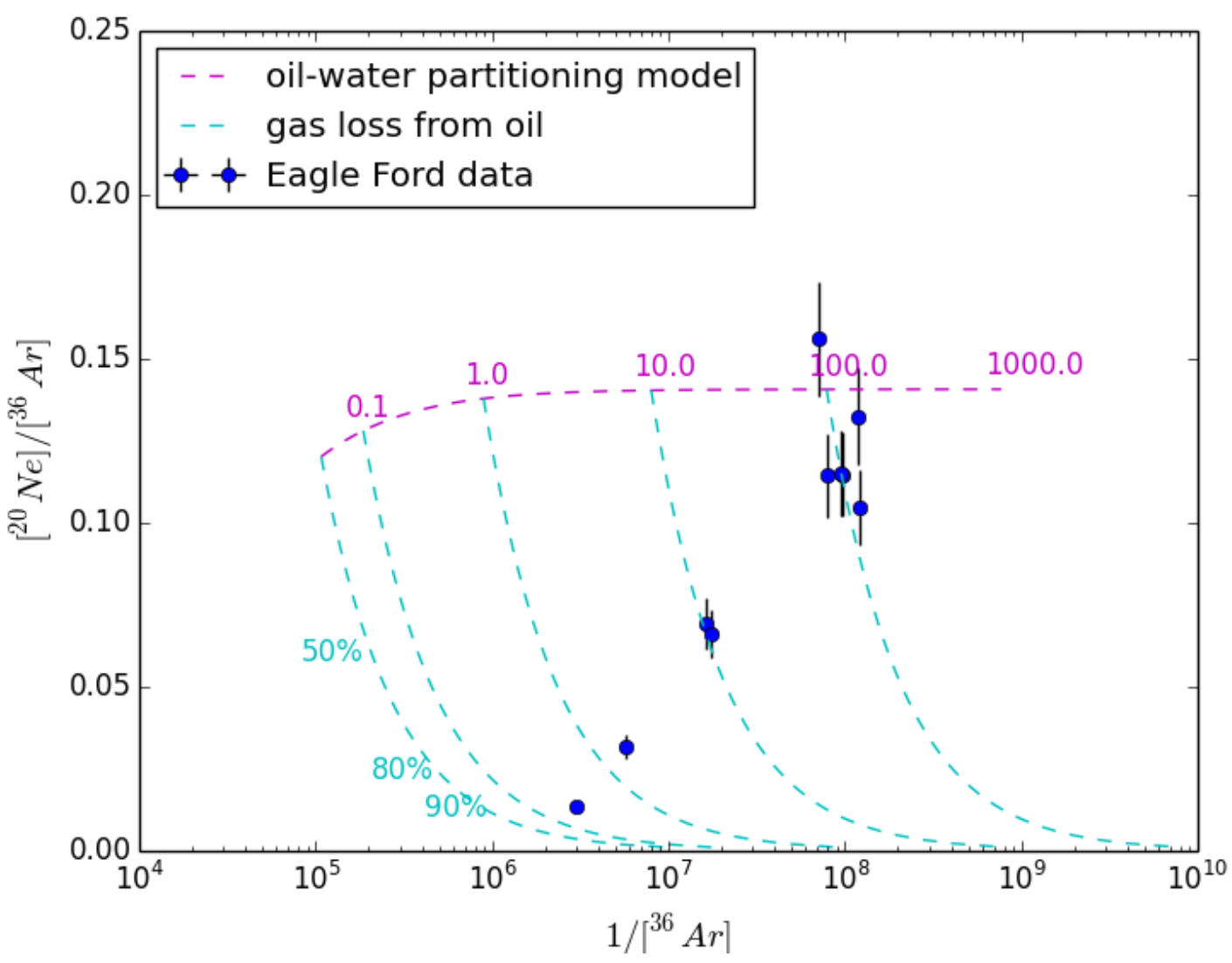


Figure 1

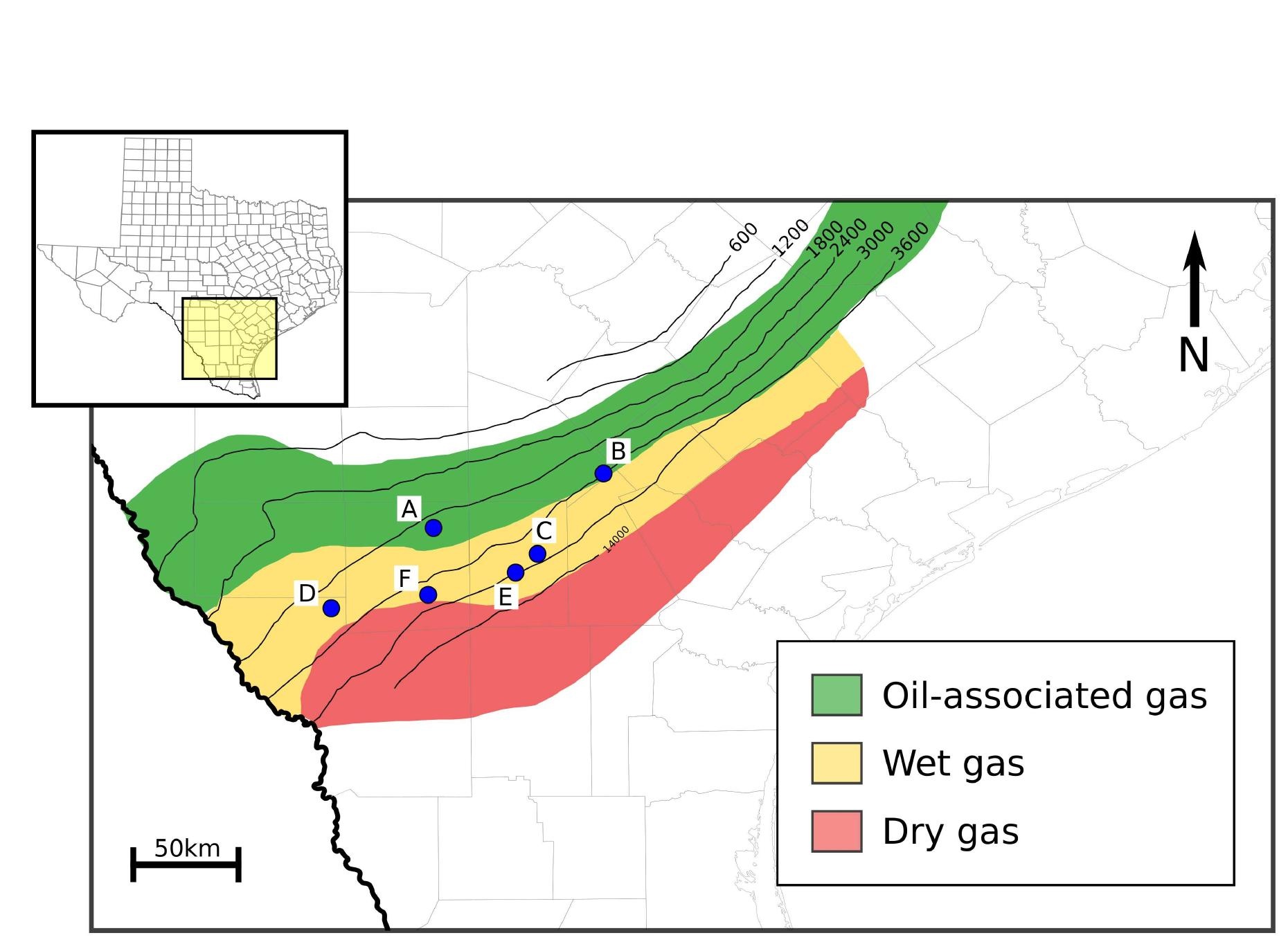

Figure 1 


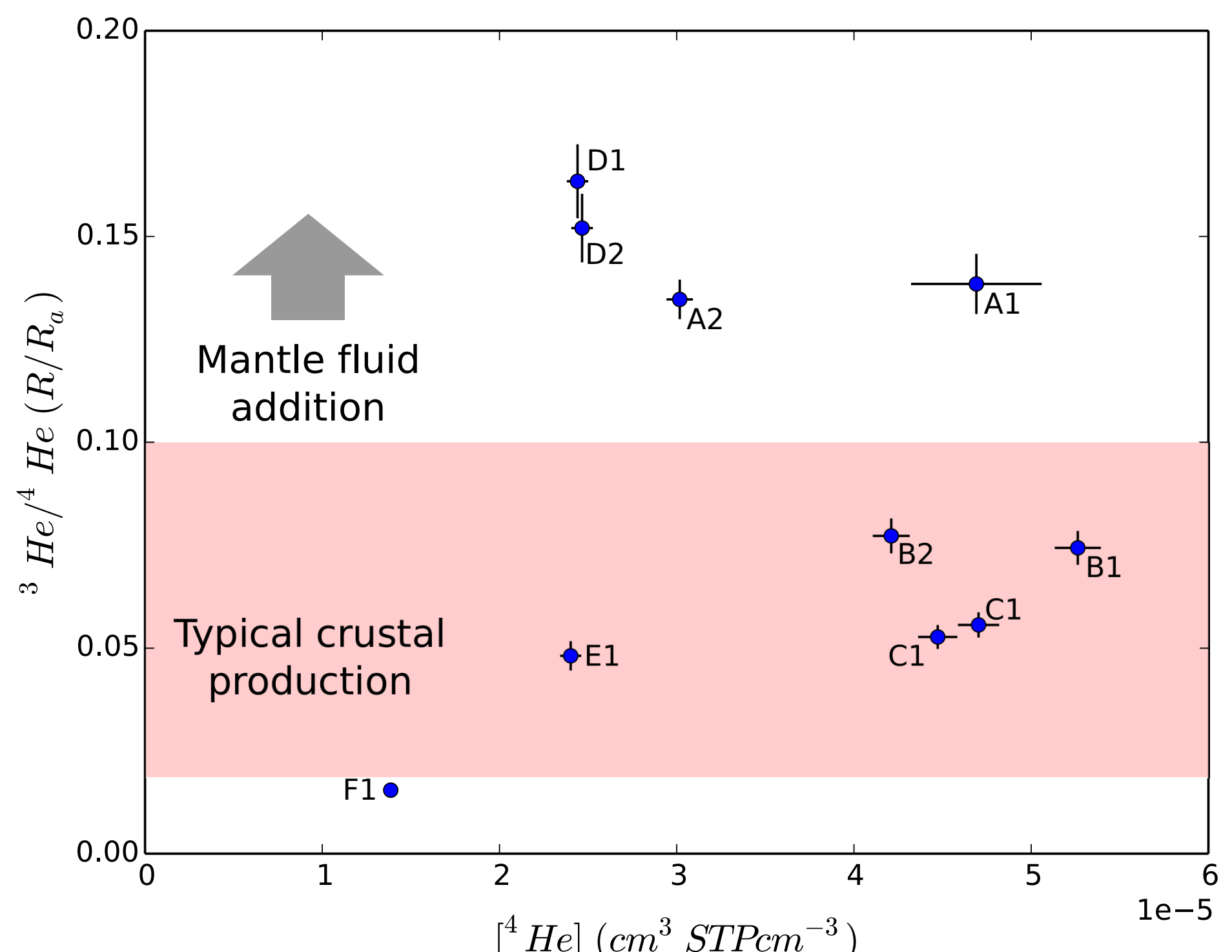


Figure 3

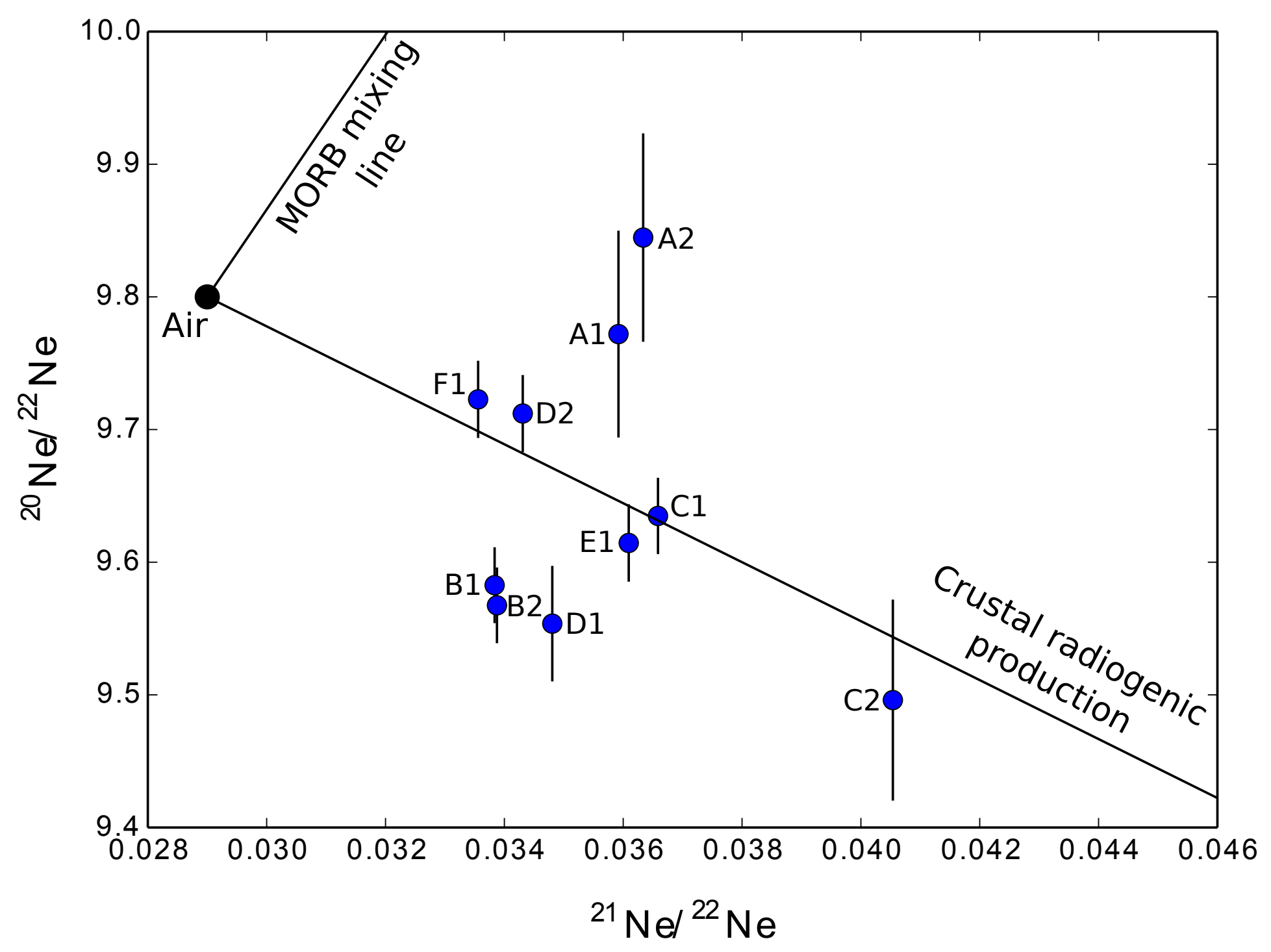


Figure 4

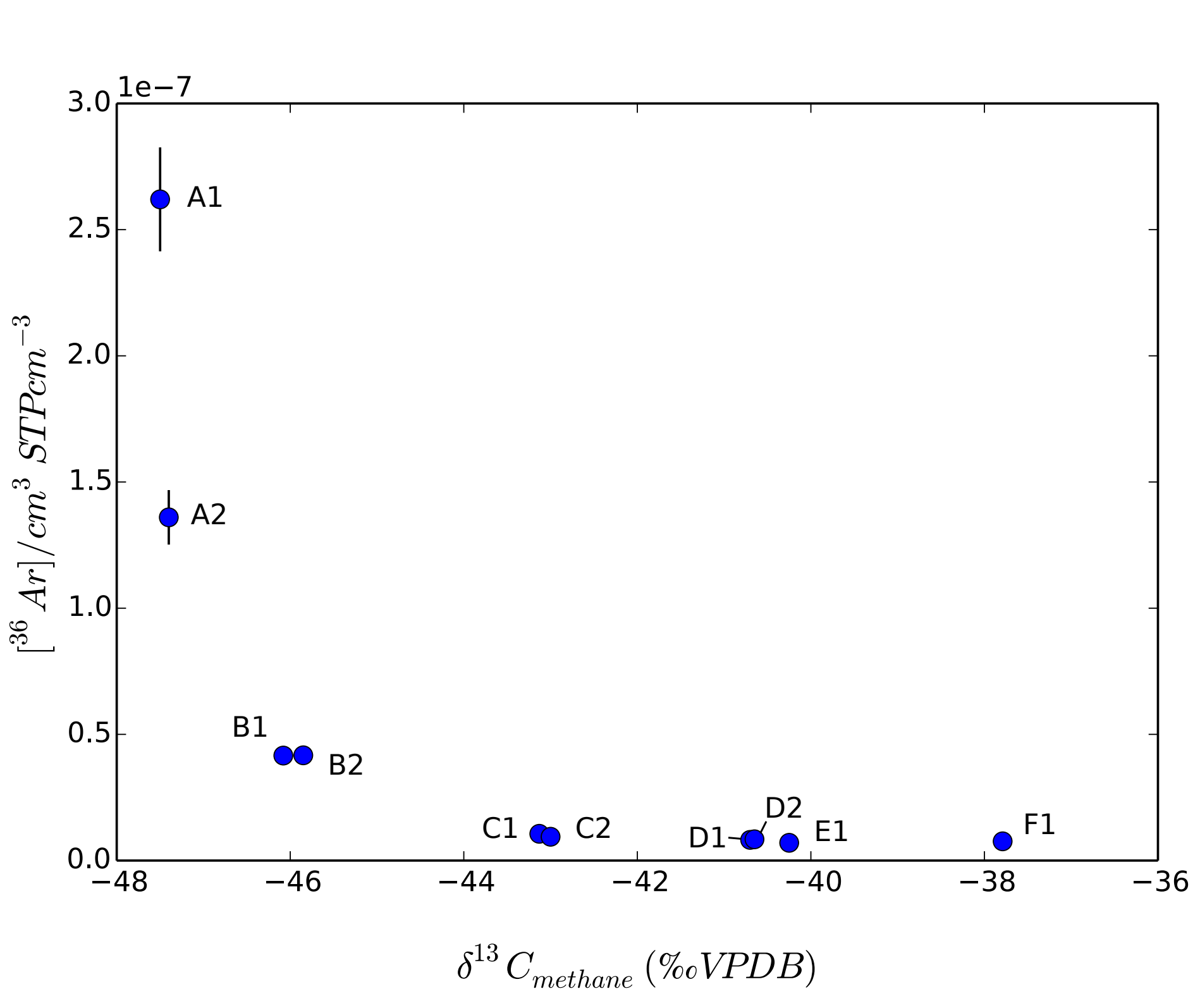

6

4


Figure 5

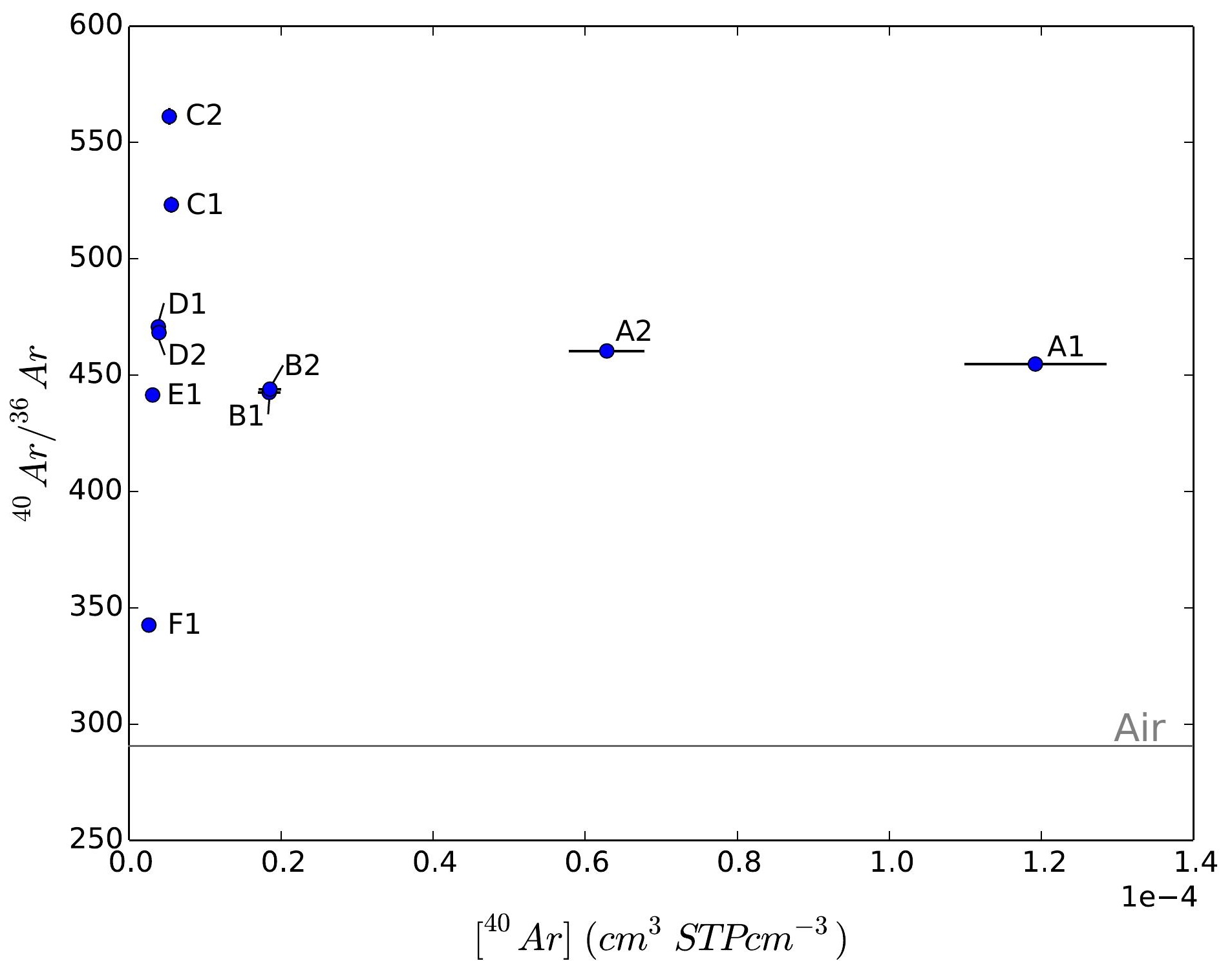

$\left[{ }^{40} \mathrm{Ar}\right]\left(\mathrm{cm}^{3} \mathrm{STP} \mathrm{cm}^{-3}\right)$ 


\section{Click here to download high resolution image}

Petroleum system 

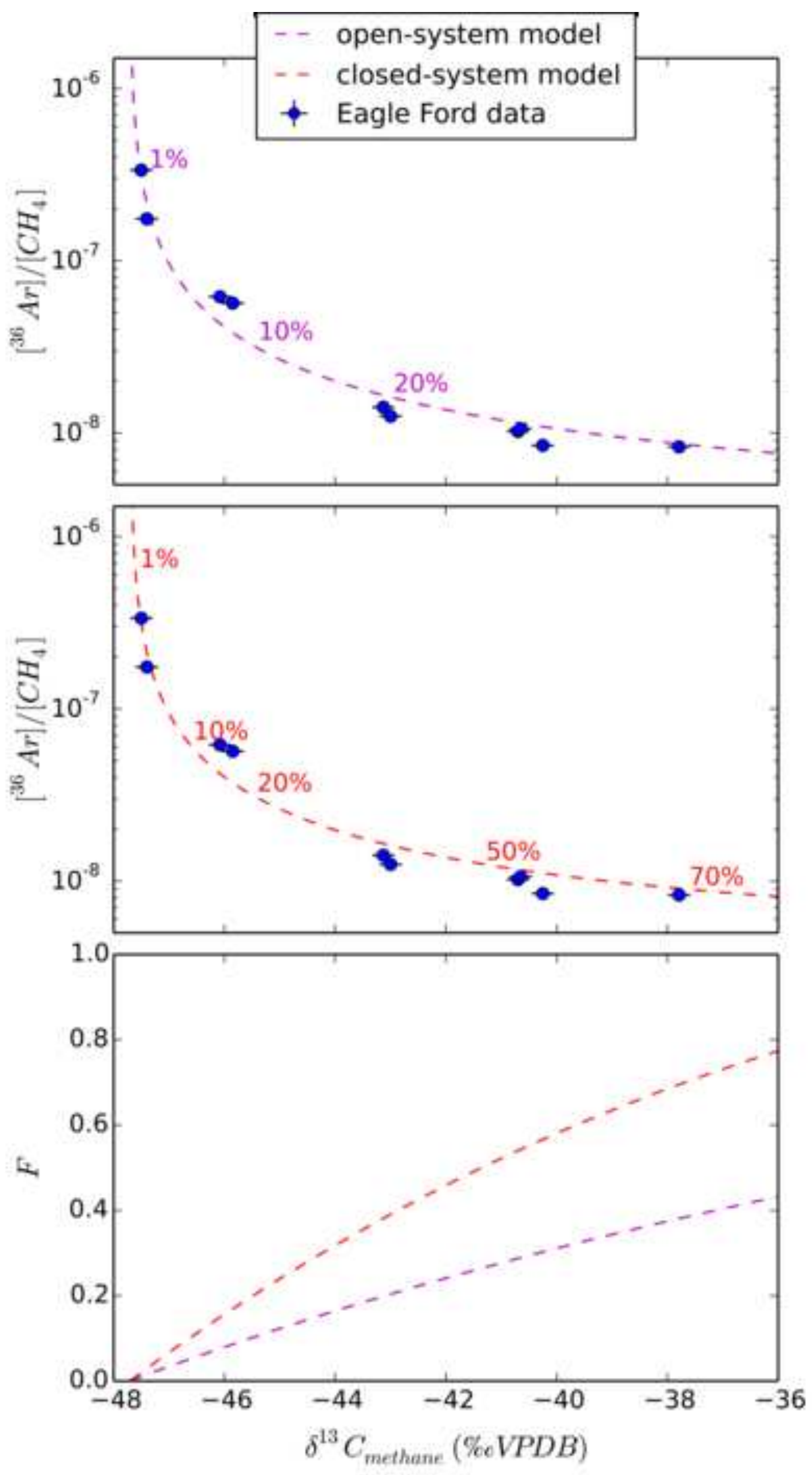


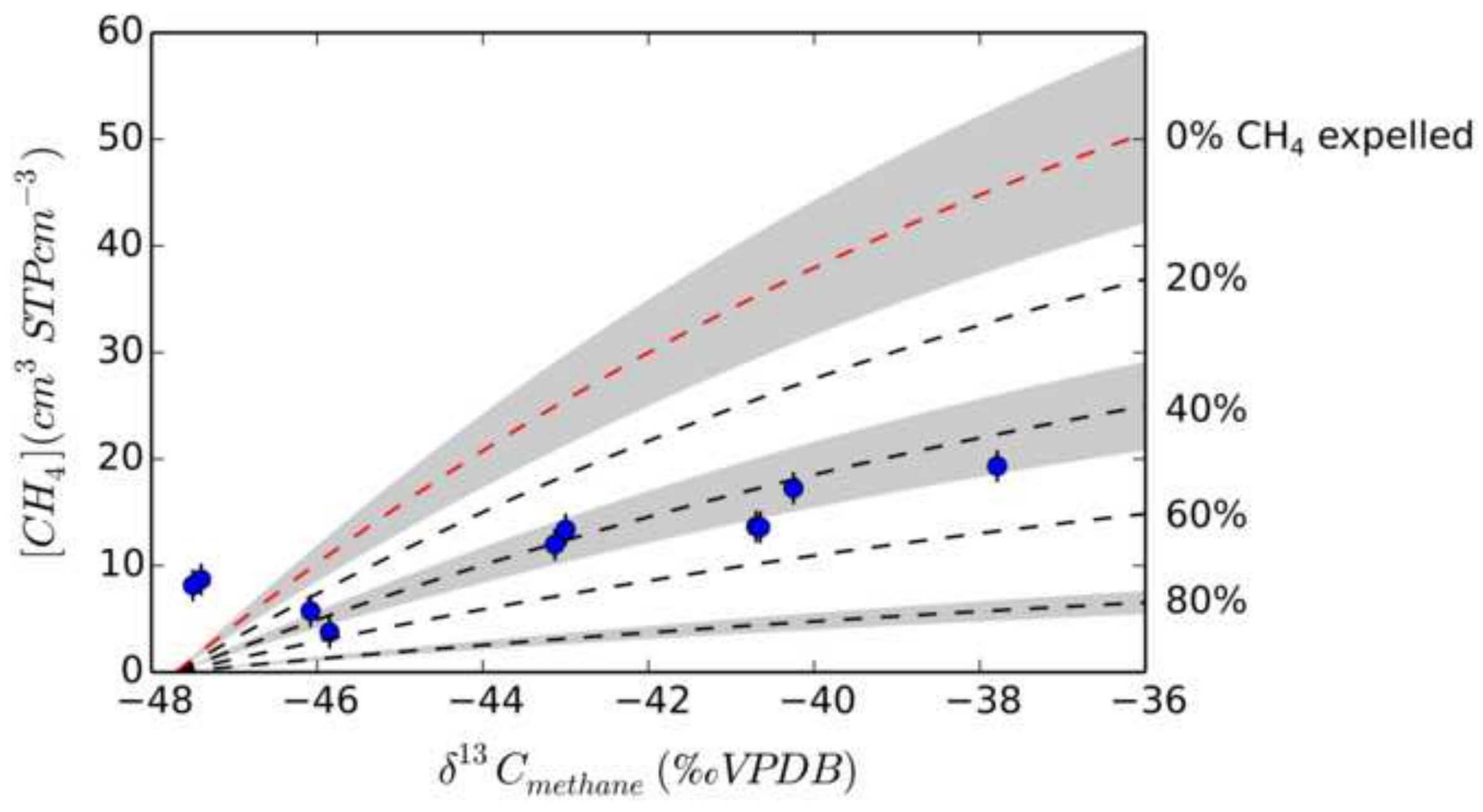



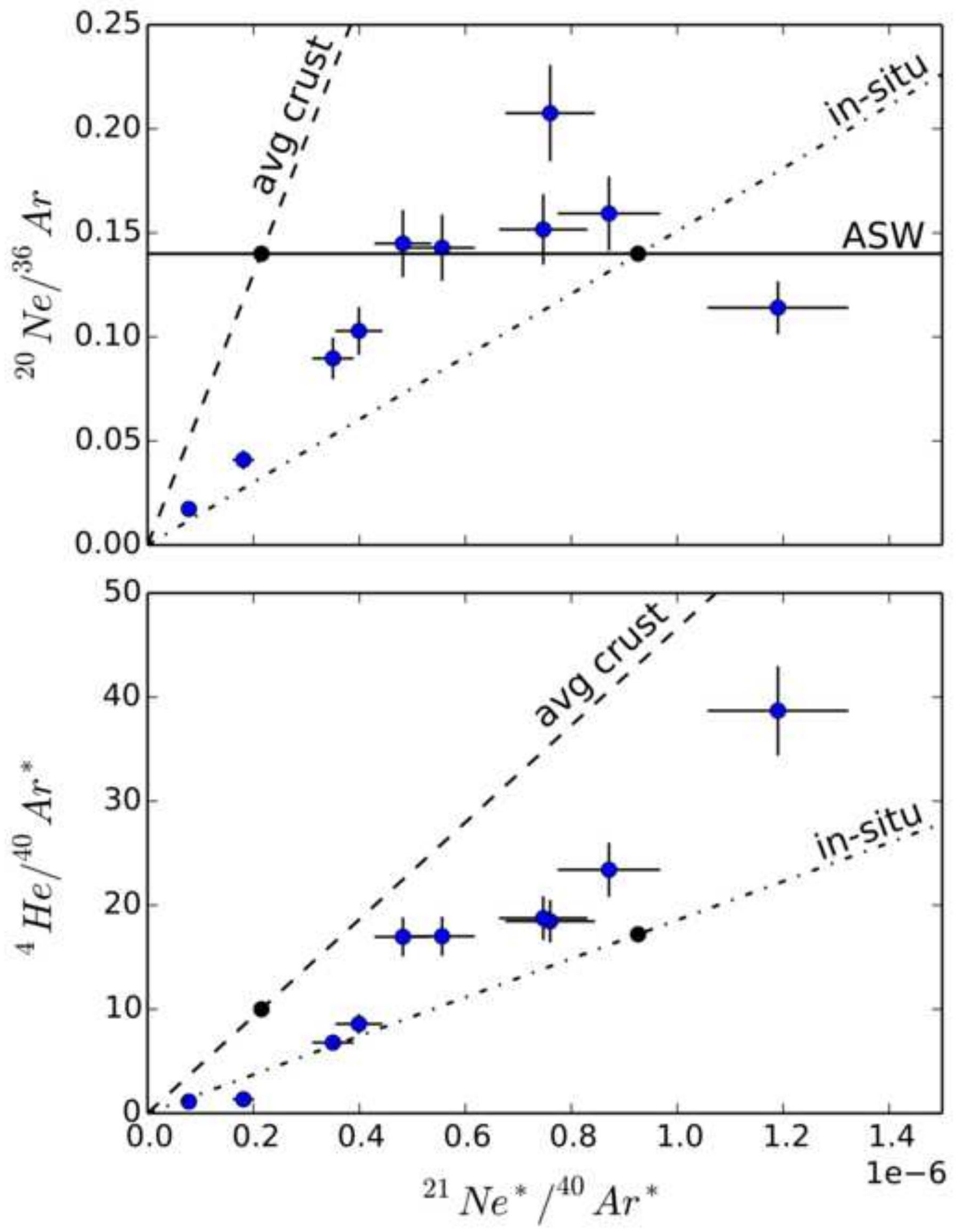


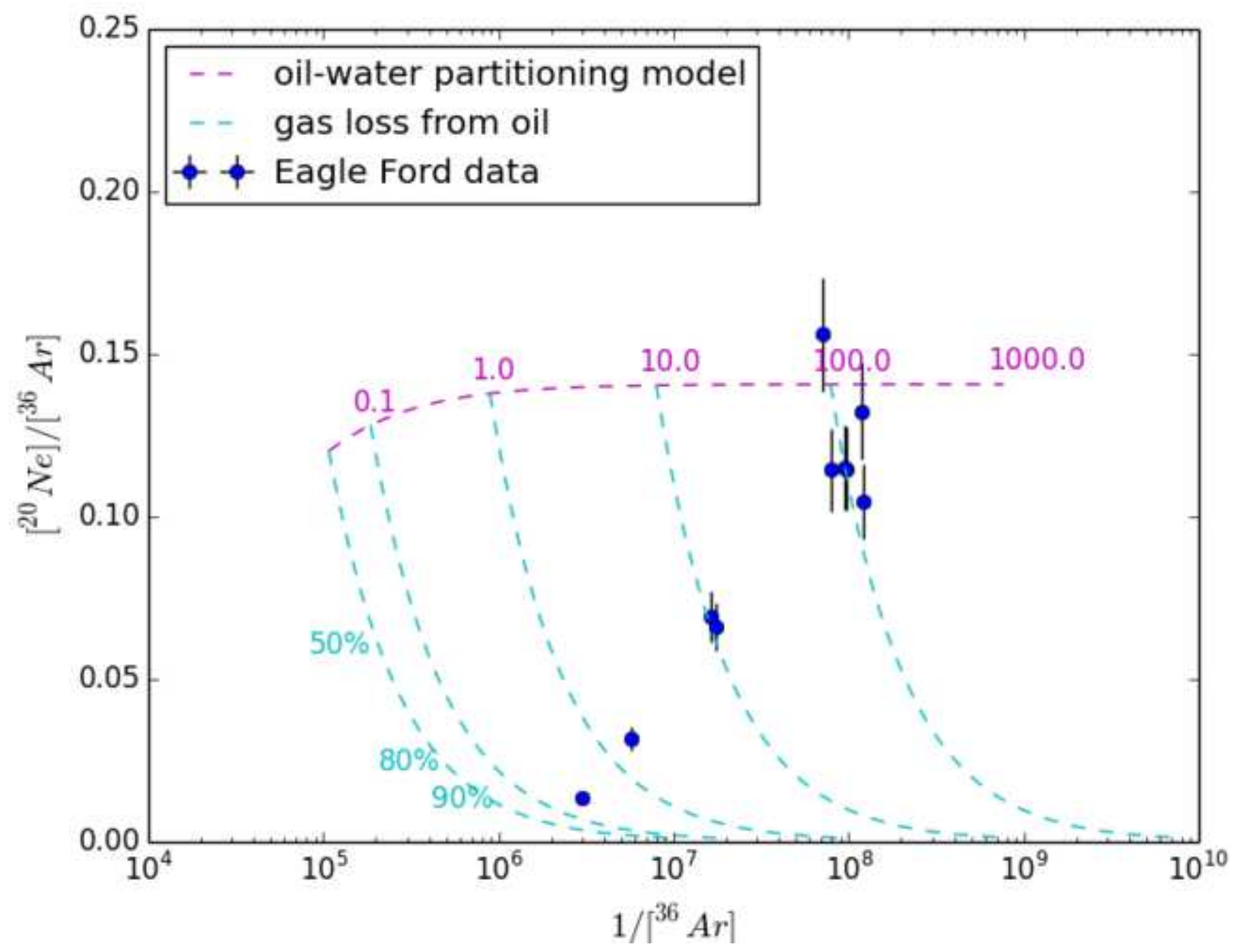

